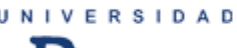 \\ REVISTAS CIENTÍFICAS DE LA
}

Cómo citar este trabajo: Aroca Vicenti, Fernando (2020). Vino, bodega y ciudad en el Jerez del siglo XVII, 03, 1-27.

https://doi.org/10.46661/bajoguadalquivirmundosatl.5433

\section{Vino, bodega y ciudad en el Jerez del siglo XVII}

\author{
Jerez, 17th Century. Wine, wineries and town
}

\author{
Fernando Aroca Vicenti \\ Universidad de Sevilla \\ viarfe37@gmail.com \\ https://orcid.org/0000-0001-7768-2829
}

\section{Resumen}

Este trabajo pretende abordar una aproximación a la actividad vinícola y su repercusión urbana en la ciudad de Jerez de la Frontera durante el siglo XVII, con el apoyo de fuentes documentales inéditas. Dicha actividad industrial, desarrollada aún en el contexto de un marcado proteccionismo, será clave para entender el desarrollo económico de la ciudad, constituyendo sólidas bases para lo que un siglo después supondrá el despegue hacia una industria moderna.

Palabras clave: Jerez de la Frontera, vino, bodega, urbanismo, ciudad, siglo XVII

\section{Abstract}

This work aims to make an approach to the wine activity and their urban impact in the city of Jerez de la Frontera during the 17TH century, with the support of unpublished documentary sources. This industrial activity, even in the context of a marked protectionism, will be key to understanding the economic development of the city, constituting a solid foundation for what a century later will result in take-off towards a modern industry.

Key words: Jerez de la Frontera, wine, Winery, urbanism, city, 17TH century 
El desarrollo vinícola jerezano y sus bodegas es objeto de interés creciente, con estudios cada vez más sólidos sobre el periodo de finales de la Edad Media así como del siglo $X \mathrm{XI}{ }^{1}$. Las investigaciones sobre los siglos XVIII al XX han proporcionado análisis más diversos, tanto desde el punto de vista económico y social como patrimonial ${ }^{2}$. Sin embargo, existe hasta el momento en este ámbito un gran vacío sobre la época central de la Edad Moderna, fundamentalmente el siglo XVII. Salvo algunos aspectos tratados en la inacabada Historia de Jerez de la Frontera, de Sancho de Sopranis, poco más se ha estudiado al respecto y casi nada sobre el aspecto patrimonial bodeguero. Con el presente trabajo queremos contribuir, pues, a un primer acercamiento a esta materia como base a futuros trabajos, con la ayuda de una amplia documentación inédita, extraída principalmente de las Actas Capitulares municipales así como de los Protocolos Notariales, desde 1600 a 1700.

1 SANCHO DE SOPRANIS, Hipólito: Documentos para la Historia del Vino de Jerez. Jerez, 1959. A este clásico hay que añadir los más recientes: MARTín GUTIÉRREZ, Emilio: «El viñedo en la zona jerezana a fines de la Edad Media». En MALPICA CUELLO, Antonio, PEINADO SANTAELLA, Rafael G., FÁBREGAS GARCÍA, Adela (eds.): Historia de Andalucía. VII Coloquio, Universidad, Granada, 2009, 287-300, págs. 288-291 (edición CD). MARTíN GUTIÉRREZ, Emilio: "Las bodegas en Jerez de la Frontera a fines de la Edad Media". Estudios sobre patrimonio, cultura y ciencias medievales, 19, 2017, pp. 847-874. GUERRERO VEGA, José M. y ROMERO BEJARANO, Manuel: "The origins of the wine house architecture in Jerez de la Frontera. Analysis of the bodegas built in the sixteenth and in the seventeenth centuries". Proceedings of the second international congress on construction history, vol. II, Cambridge, 2006, pp.1441-1454.

\section{Introducción. Viña, vino y vinateros}

Pese al estancamiento y crisis económica generalizada en toda la península, con ausencia de recuperación demográfica tras las mermas derivadas de las epidemias, bajas en campaña y emigración a las Indias, la producción vinícola y su comercio continuaba su proceso en la ciudad, con la consabida repercusión urbana, que aunque lejos de alcanzar los niveles de la siguiente centuria no debemos restarle importancia. Como ya apuntaba Sancho de Sopranis, a comienzos de siglo la vinatería jerezana mostraba un claro descenso, aunque con el paso de los años se producirá un aumento de la extensión del viñedo, que, dado su rentabilidad, aventajaba en buena medida al olivar. Este autor señala una estadística del volumen de exportación para el año 1643, con 9435 botas de vino y vinagre y 3250 quintales de pasas ${ }^{3}$. Para el comercio exterior durante la segunda mitad de siglo, sobre todo a Inglaterra, se conocen nuevos datos que ponen de relieve el predominio los caldos jerezanos y zonas

2 MALDONADO ROSSO, Javier: La formación del capitalismo en el marco del jerez. De la vitivinicultura tradicional a la agroindustria vinatera moderna (siglos XVIII y XIX). El Puerto de Santa María, 1998. AROCA VICENTI, Fernando: De la ciudad de Dios a la ciudad de Baco. La arquitectura y urbanismo del vino de Jerez (siglos XVIII-XX), Jerez, 2007. ALADRO PRIETO, José M.: La construcción de la Ciudad Bodega arquitectura del vino y transformación urbana en Jerez de la Frontera en el siglo XIX. (Tesis doctoral inédita), Universidad de Sevilla, 2012.

3 SANCHO DE SOPRANIS, Hipólito y LASTRA Y TERRY, Juan de la: Historia de Jerez de la Frontera. Desde su incorporación a los dominios cristianos. T. III. La decadencia (siglo XVII). Jerez, 1969, cap. VI, pp. 310. 
próximas -Sanlúcar, El Puerto de Santa María y Rota- desembarcados en Londres y Bristol frente a otras zonas productoras españolas ${ }^{4}$.

La relevancia de la actividad vitivinícola en el Jerez del Seiscientos queda atestiguada por muchos documentos de la época, que, aunque referidos a asuntos diversos, suelen aludir al vino como la principal base del comercio de la ciudad. Así se expresa, por ejemplo, en las reiteradas quejas de los comerciantes y vinateros ante el mal estado de la calzada y muelle del Portal. En 1615 los cargadores a Indias vecinos de la ciudad se referían a este comercio como: ...el mayor que hay en ella y de donde se sustentan los demas... ${ }^{5}$, y 1621 los comerciantes expresaban la pérdida de ...la renta y alcabalas del bino y millones que montan mas de cuarenta mil ducados cada año y de aduana y almoxarifasgo... ante la decisión de adquirir vinos en otros lugares como Sanlúcar, Rota, El Puerto de Santa María y Chiclana, por el mal estado de la mencionada calzada ${ }^{6}$.

Los sectores profesionales desarrollados en torno al mundo vitivinícola local son prácticamente los mismos que vemos un siglo más tarde, cuando el florecimiento de esta industria inicie su camino hacia la modernidad. De esta forma, los viticultores o cosecheros cultivaban la vid para la posterior elaboración de mostos y vinos, mientras que el grupo de comerciantes abarcaba a los factores, cargadores a Indias, exportadores e incluso bodegoneros ${ }^{7}$. Como ya señaló Sancho de Sopranis, pese a la importancia de esta actividad tanto en Jerez como en otras poblaciones cercanas, no existía un gremio de la vinatería que la regulara, por lo que comúnmente se recurría a la Ciudad como

${ }^{4}$ MARTÍNEZ RUIZ, José I: “El comercio de vinos entre España e Inglaterra en la segunda mitad del siglo XVII". Historia Agraria, 70, diciembre 2016, pp. 1146.

5 RÍOS MARTíNEZ, Esperanza de Los: Antón Martín Calafate y Diego Moreno Meléndez en la arquitectura jerezana del siglo XVII. Cádiz y Sevilla: Universidad, 2003, p. 62. mediadora ante cualquier vicisitud, ya que hasta 1733 no se llevan a cabo las ordenanzas de tal gremio.

La documentación consultada nos permite conocer una gran división de la superficie del viñedo, en manos de diferentes sectores de la sociedad, desde las clases altas -nobleza y clero- a una incipiente burguesía de comerciantes, sin olvidar tampoco a algunos trabajadores de oficios menestrales que deciden invertir -en la medida de sus posibilidades- en el cultivo de la vid. Los abundantísimos contratos de compraventa y arrendamientos de viñas incluyen pequeñas tierras, que no superan por lo general las diez o doce aranzadas, predominando las transacciones con superficies desde la media a las cinco aranzadas. Los pagos donde se localizan las viñas que aparecen habitualmente son: Abiertas de Caulina, Alcántara, Almocadén, Añina, Arroyo del Membrillar, Baladejo, Balbaína, Valdepajuelas, Barbadillo, Bogas, Burujena, Cantarrana, Cañada del Puerto, Capirete, Carrascal, Cerro del Bonete, Cerro del Buey, Cerro del Judío, Cerro de Santiago, Corchuelo, Cuartillos, Duchas, Espartinas, Haza del Caballo, Hernán Ruíz, La Doncella, La Gallega, La Granja, La Norieta, La Serrana, La Zarzuela, Lomos de San Lázaro, Los Manzanillos, Los Yesos, Macharnudo, Manjón, Maricuerda, Matacardillo, Montana, Montealegre, Orbaneja, Parpalana, Picadueñas, Pie de Rey, Rabo de Atún, Rincones, Rui Díaz, San Julián, Sangarriana, Segullo, Sierra de San Cristóbal, Solete, Tizón, Tocina, Torrox, Valcargado y

6 Archivo Municipal de Jerez de la Frontera (AMJF). Actas Capitulares (AC), 1621. Fol. 22.

7 Este es el esquema planteado para el siglo XVIII en MALDONADO ROSSO, Javier: La formación del capitalismo, p. 61 
Valdepajuelas, algunos de los cuales ya se tiene constancia desde la Baja Edad Media ${ }^{8}$.

La producción de caldos se enfocaba mayoritariamente a los productos básicos, como eran los mostos y vinos en claro de la cosecha, tal y como continúan elaborándose hasta la década de los sesenta del siglo XVIII ${ }^{9}$, aunque no faltaron los añejados. No obstante resulta difícil precisar las características específicas de los vinos producidos durante el Seiscientos en la ciudad, por lo que es necesario recurrir a los documentos que, si bien no aportan datos concluyentes, nos ayudan a ilustrar de alguna manera esta cuestión. Las alusiones más frecuentes corresponden al mosto, vino de yema, aguapié y espirriaque. El mosto de yema era el obtenido de la primera pisa de la uva; el aguapié el resultante de la segunda pisa, que al mezclarse con agua rebajaba la acidez; por último el espirriaque era el mosto obtenido en

8 MARTÍN GUTIÉRREZ, Emilio: La organización del paisaje rural durante la Baja Edad Media. El ejemplo de Jerez de la Frontera. Cádiz: Universidad, 2004.

9 MALDONADO ROSSO, Javier: La formación del capitalismo, p. 76.

10 PEMARTín, Julián: Diccionario del vino de Jerez. Barcelona, 1965, pp. 10 y 106 . Son muy abundantes las alusiones a estos elementos, generalmente en las transacciones de ventas de caldos. Como ejemplo podemos tomar la venta que Álvaro de Soto Dávila hace a Francisco de Zurita y Haro, clérigo de órdenes menores, de "...cuatro caldos de bota de aguapié y mosto de sus viñas en pago de Burujena de la cosecha de este año...a precio de cinco ducados cada uno...", así como “... un caldo de bota de yema de esta mesma cosecha en precio de ocho ducados y asimismo le entregare dieciocho arrobas de esperriaca...", Archivo de Protocolos Notariales de Jerez de la Frontera (APNJF), Diego de Soto Guerrero, 1653. Fol. 256.

11 GONZÁLEZ GORDON, Manuel M: Jerez-XerezSherrish. Jerez, 1970, pp. 266-267. Como ejemplo sirva la venta que Martín Resero hace a Simón Juanes, mercader flamenco vecino de Sanlúcar, de 50 quintales de yeso blanco, bien cocido y a contento de su capataz Francisco Franco para "...las vendimias deste presente año...", a precio de un real y medio cada quintal, APNJF, Juan Bautista Bousomo, 19 de abril de 1621. la tercera tira, de rango muy inferior ${ }^{10}$. Tenemos también constancia del empleo del yeso, con toda probabilidad tal y como se ha usado tradicionalmente en los lagares de la comarca de Jerez, para dar consistencia a la masa de uva pisada ${ }^{11}$.

Aunque la mayor parte de la producción eran vinos claros, se alude a veces a los tintos, en la documentación reflejados como tinta. También aparecen otras denominaciones, como vino padrón, vino redondo, vino madreado y tahilado o vino bueno ${ }^{12}$. Los vinos más dulces se elaboraban a través de la uva Pedro Ximenez ${ }^{13}$. Contamos también con una singular referencia hallada en una partición de bienes, donde figuran entre los caldos tres botas de vinagre, otras tres de bino padrón y otras de mosto cocido, así como dos botas de vino fino llenas... a quince ducados cada una... ${ }^{14}$ (Figura 1). Es esta la única vez que, hasta el momento, aparece esta

12 En un cargamento para las Indias se mencionan cuarenta pipas de vino, entre las cuales se incluyen tres de tinta y tres de vino cocido, APNJF. Juan Vázquez de Astorga, 9 de junio de 1608. Esta información aparece también a veces en las particiones de bienes tras los testamentos. Así, en la partición de los bienes que quedaron por fallecimiento de D. Juan Muniel de Jenes figuran cinco botas de vino redondo con 28 arrobas cada una y otras 20 arrobas de vino bueno, así como 17 botas de vino dañado y vinagre de 28 arrobas cada una, APNJF, Francisco Ignacio de Magallanes, 1681. Fol. 54. En la partición de los bienes tras el fallecimiento del jurado D. Alonso Pacheco Patrite aparecen una bota de padrón y tres botas de tinta, APNJF, José de Castro, 1690. Fol. 142. En la partición de los bienes de D. Diego Lambaret figuran 74 caldos de vino bueno que bajadas las melmas quedan en sesenta y cinco caldos, así como 24 caldos de vino madreado y tahilado y ocho caldos de vinagre, APNJF, Lorenzo Meléndez, 1695. Fol. 60.

13 APNJF. Juan Gómez Rendón, 1652. Fol. 334. Juan Jiménez, clérigo de menores, se obliga a entregar a Fernando Guillén, presbítero, cuatro caldos de mosto de Pedro Ximenez, de sus viñas en pago de Macharnudo, a precio cada caldo de cien reales de vellón.

14 APNJF. Diego González de Trujillo, 1650. Fol. 1. Se trata de la partición de bienes por fallecimiento del jurado Antonio Bermúdez, donde figuran también 
denominación que, como cabe suponer, no debe guardar relación con el Vino Fino, cuyo origen y desarrollo ocupó buena parte del siglo XIX y primeros años del $X X^{15}$, por lo que debió tratarse de un simple adjetivo para referirse a un vino posiblemente más ligero, pues el precio indicado por cada bota no era superior a las otras referidas.

Con relación a los tipos de vinos, no podemos olvidar la curiosa apreciación que el cronista local Sebastián Marocho hacía en 1658: ...en los bautismos solo se gastaban garbanzos tostados, si eran pobres, y si con algún posible pasas de sol y avellanas, pero en ambos ricos vinos, y mientras más colorado el vino más estimado... ${ }^{16}$.

Lo que sí podemos asegurar es el común empleo del mosto cocido para fortalecer los caldos, cuando el tiempo impedía el soleo de la uva, como aparece casi siempre reflejado en las compraventas, cuyas transacciones se realizaban entre los cosecheros, vinateros y comerciantes. Sería interminable exponer aquí la lista de operaciones de venta de caldos de las que tenemos constancia documental, en cuyas condiciones se exige la bondad de la

las casas principales de su morada en calle Cantarería con dos bodegas en su interior, así como cuatro aranzadas de viñas más otras quince en el pago de Orbaneja y otras cinco en el de Montealegre.

15 MALDONADO ROSSO, Javier: "En torno a los comienzos del Fino como tipo de vino diferenciado". En MALDONADO ROSSO; Javier (ed.): Actas de las I Jornadas del Vino Fino. El Puerto de Santa María: Ayuntamiento, 1996, pp. 31-60.

16 MAROCHO, Sebastián: Cosas notables ocurridas en Xerez de la Frontera desde 1647 a 1729. Larache, 1939, p. 22.

17 De la abundante documentación tomaremos solo algunos ejemplos. En 1619 el vinatero Francisco Meléndez vende a Sebastián Franco y Pedro Carrasco, de El Puerto de Santa María, seis caldos de botas de mosto, cuatro de uva palomina y dos de una vejeriega, buena y madura, con cuatro días de sol, o si el tiempo lo impide dándole a cada bota dos jarras de mosto cocido, APNJF, Francisco Arias de Gallego, 17 de noviembre de 1619. En 1651 Cristóbal Martín, maestro tonelero, vende al uva: buena, madura, cogida en tiempo y sazón, dándoles dos días de sol -en algunos casos hasta cuatro-, o en su defecto añadiéndose a cada bota dos jarras de mosto cocido ${ }^{17}$. Este último constituía además la base para la elaboración del arrope, producto muy utilizado como condimento, conservas de fruta y otros elementos, que en esta zona se obtenía mediante la concentración del mosto en calderas de cobre a fuego directo, reduciéndose a la quinta parte de su volumen ${ }^{18}$, cuya calidad se solía medir por su color intenso y adecuada cocción $^{19}$. La producción del mosto cocido, tanto para el fortalecimiento de vinos como para la elaboración del arrope, fue intensa a juzgar por la asiduidad con que aparecen reflejadas las calderas de cobre para la cocción en inventarios de bienes y otros documentos de compraventa de viñas.

En cuanto a los tipos de uva, las citadas con más frecuencia son la "palomina", "vejeriega", "almuñécar" y "pedro ximenez".

De cara a la venta, se generalizaba la clasificación en vinos nuevos y vinos añejos. Pese a que el principal volumen para la

escribano Francisco Gallegos cuatro caldos de mosto de su viña de cinco aranzadas en pago de Cuartillos, ...de buena uva madura, coxida en tiempo y sazon dándole dos días de sol y si no ubiere le dare por cada un caldo de bota de mosto dos xarras de mosto cosido...APNJF, 1651, Gabriel Ramírez de Arellano. Fol. 61. En este caso, como vemos, el propietario de la viña es un menestral relacionado con el mundo vinícola, tratándose de un tonelero. En 1668 Andrés y Domingo González venden a Andrés Martínez, clérigo de menores, ocho caldos de mosto de su viña de cinco aranzadas en Cuartillos...eceptuando los aguapies... porque las que asi entregaremos an de ser de yema..., dándole dos días de sol, o si no una arroba de mosto cocido a cada bota, APNJF, Gabriel Ramírez de Arellano, 25 de diciembre de 1668.

18 GONZÁLEZ GORDON, Manuel M: Jerez, p. 326.

19 En 1621 Gonzalo Martín vende al médico Pedro Leonardo dos caldos de botas de arrope ...buenos y bien cosidos y negros y finos de buena uba..., APNJF, Francisco Gómez de Mirabal, 31 de diciembre de 1621. 
exportación lo constituían los vinos nuevos, en el consumo local debieron prevalecer los añejos, como se deduce de las abundantes quejas elevadas al Cabildo para que autorizase el consumo del primero cuando escaseaba este último. Contamos con varias peticiones al respecto, siempre referidas a las ventas en tabernas locales, algunas de las cuales llegaban a cerrar ante la falta de caldos añejados, como ocurrió en los años 1642, $1645,1651,1652,1654$ y 1656, en los que el Fiel Preceptor de los derechos de millones del vino de tabernas eleva la pertinente queja al Cabildo para que permita la venta del vino joven ante la escasez del viejo. Una vez justificadas las peticiones, la Ciudad solía autorizar la venta de los caldos de la cosecha del año, aguapié y otros ${ }^{20}$.

Otro hecho significativo fue la entrada de vino foráneo, con precio de venta más bajo, algo frecuentemente denunciado por los vinateros locales al afectar seriamente a sus negocios. Un ejemplo es suficiente para ilustrar este hecho: en 1676 un grupo de vinateros se quejaban por abastecerse las tabernas de vino forastero desde hacía algún tiempo, alertando del peligro para la economía de la ciudad, expresando: ...de los mayores tratos que ay en esta dicha ciudad para su conservación es la vinatería y este es tan esencial que si faltara se pudiera despoblar gran parte della ... de poco tiempo a esta parte todos los taverneros an dado en abastecerse para el gasto de sus

20 AMJF. AC, 1642. Fol. 22: Juan Ximenez de los monteros fiel Preceptor de los derechos de los millones del vino...de tabernas desta ciudad digo que por la falta de vino añejo estan mas de la mitad de las tabernas sin bender vino por cuya causa tienen muy gran daño a la real hacienda de su magestad... pido y suplico sirba de mandar se de licencia para que se pueda bender bino nuevo en las dichas tabernas... AC, 1645. Fol. 307: El mismo Juan Jiménez hace la misma petición y obtiene licencia de la Ciudad para ...que se pueda vender aguaspies para el avasto y Proveimiento desta ciudad respecto de la falta que ay de bino añexo... En 1652, ante la falta de caldos y la entrada de vino de Lucena, se pide permiso al corregidor para la venta de vino nuevo, autorizándose el de la cosecha pasada, tabernas de vinos forasteros con titulo de lucena siendo de utrera y de otras partes que metedores se los ponen en sus casas en grave daño y menoscabo de la Real acienda y perjuicio de los vecinos ... y todas las ciudades de la comarca considerando lo referido en virtud de los previlegios que tienen...an ataxado la entrada de dicho vino en sus lugares...pedimos...mande acordar que no se consienta bender en taverna alguna vino forastero ni se permita entrar en dicha ciudad y el que allare se derrame... ${ }^{21}$.

Del mismo modo la introducción de caldos jerezanos en otros núcleos, como El Puerto de Santa María, encontró también el rechazo de sus comerciantes y vinateros. Así, en 1698 un grupo de cosecheros jerezanos manifestaban el impedimento de aquella ciudad para vender sus vinos, llegando incluso a confiscarlos y derramarlos por el suelo, por lo que solicitaban al Cabildo de Jerez rescatar de su archivo un privilegio dado por el Real Consejo de Valladolid el 30 de enero de 1515, que autorizaba a los cosecheros a llevar el vino a la ciudad de El Puerto ${ }^{22}$. Todo ello debió ser consecuencia de la ejecutoria ganada por los cosecheros de esta última ciudad ante el Consejo de Castilla en 1686 para impedir la recepción de caldos foráneos ${ }^{23}$.

Especial relevancia tuvieron los cosecheros y vinateros gaditanos, muchos de ellos instalados ya en la ciudad. Durante este siglo Cádiz comenzaba una prosperidad auspiciada

aguapié y mixtos, AC, 1652. Fol. 517. AC, 1654. Fol. 309 vto. AC, 1656. Fol. 1496: Ante la misma petición, la Ciudad acordó: ... que se de licencia para que por agora puedan vender los aguaspies y otros que ubieren cogido en la cosecha de este presente año...

${ }^{21}$ AMJF. AC, 1676. Fol. 985 vto.

${ }^{22}$ AMJF. AC, 1698. Fol. 609.

23 IGLESIAS RODRIGUEZ, Juan J: "La vitivinicultura en el Marco del jerez entre finales del siglo XVII y mediados del XVIII". En RAMOS SANTANA, Alberto y MALDONADO ROSSO, Javier: El jerez-xèrés-sherry en los tres últimos siglos. El Puerto de Santa María, 1996, p. 41. 
por el comercio con Indias, que llegará a su cénit en la siguiente centuria, a raíz del traslado de la Casa de Contratación desde Sevilla en 1717. Su interés por el vino de Jerez no miraba solamente al comercio exterior, sino también al consumo interno de la ciudad, cada vez más populosa con el tráfico de navíos. En su momento ya apuntábamos el gran número de comerciantes gaditanos que invirtieron en el negocio vinícola durante los siglos XVIII y XIX ${ }^{24}$, hecho que, como vamos a ver a continuación, era ya una realidad durante el Seiscientos.

Muchos eran los gaditanos con viñas en el término jerezano, obligados a pagar el preceptivo medio ducado por cada bota sacada fuera de la ciudad, lo que derivó en un pleito en 1645 con alegaciones al Consejo de Castilla para eludir el impuesto por ...las botas que sacaban de sus heredades por el dicho Portal [muelle] para la dicha ciudad de Cadiz... De esta forma pedían la libre salida del vino para ...llevarlo y enzerarlo en las bodegas que tengan en la ciudad de Cadiz..., argumentando que lo hacían como ...fruto de sus cosechas y no para venderlas sino para trasegarlos a las bodegas de la dicha ciudad de cadiz y consumirlo en sus casas... ${ }^{25}$. Solicitaban así una reforma de la Real Facultad que recogía el pago de medio ducado por cada bota que saliese de la ciudad para dentro y fuera del reino, argumentando como medida de presión el asentamiento de sus heredades en el término jerezano. Por su parte las autoridades locales alegaban que los cosecheros de Cádiz compraban partidas de caldos de mosto, pipas y botas de vino no solo para su ciudad sino también para fuera del

${ }^{24}$ AROCA VICENTI, Fernando: De la ciudad de Dios a la ciudad de Baco, p. 110.

${ }^{25}$ AMJF, AC, 1645. Fol. 743. En el documento aparecen un total de diez cosecheros gaditanos, en representación de todos los demás con heredades de viñas en Jerez.

${ }^{26}$ AMJF, AC, 1643. Fol. 569: .... a esta ciudad an llegado dos rexidores de la de cadiz los quales andan haciendo bisita cela y cata en muchas bodegas que reino e Indias, lo que no justificaba la exención de dicho impuesto.

Resulta interesante la mención que se hace a las bodegas de Cádiz para depositar el vino, pues como cabe suponer no eran espacios de crianza, sino más bien almacenes, dado el volumen de gaditanos con bodegas propias en Jerez, como nos revela un interesante documento relativo a una comisión de investigación por parte de las autoridades de aquella ciudad. Fechado en 1643, recoge la llegada de dos regidores gaditanos para indagar sobre las bodegas de sus paisanos, a las que irrumpieron con violencia provocando el escándalo de los vecinos, todo ello sin previa información a las autoridades locales ${ }^{26}$. A partir de este hecho se intentan establecer acuerdos entre ambas ciudades a fin de informar previamente de las visitas $y$ controles ${ }^{27}$.

También en momentos de escasa producción se solía acudir a Cádiz a comprar vino a bajo precio, en detrimento de los caldos locales, por lo que se pide en 1681 que, ante la mala cosecha y escasez de mosto, se establezcan precios razonables para la venta por botas $y$ así evitar la compra de vino en aquella ciudad $^{28}$.

\section{Vino, bodega y las epidemias de peste}

Consideradas como una de las grandes adversidades del siglo XVII en Europa, las epidemias de peste asolaron a muchas zonas de la península, con trascendentales consecuencias en el ámbito económico y, sobre todo, demográfico, hasta llegar a casos

en esta ciudad tienen muchos vecinos de la dicha Cadiz decerraxandolas y haciendo Muchos alborotos y Ruydos en lo cual an dado y dan mucho escandalo al comun...sin traer como no traen Requisitoria ni aberla intimado ante el Sr. Corregidor...

${ }^{27}$ AMJF, AC, 1645. Fol. 687vto.

${ }^{28}$ AMJF, AC, 1681. Fol. 514vto. 
extremos como el de Sevilla, cuyo embate más maligno se produjo en 1649, que llegó a reducir su población a más de la mitad ${ }^{29}$.

Aunque no de forma tan radical también las epidemias pestíferas hicieron acto de presencia en Jerez, localizadas a principios y mediados de siglo. La primera se inició en el último año de la anterior centuria, 1600, comenzando a principios de abril, para lo que se habilita un hospital en la ermita de san Benito, -habitada por frailes carmelitas- al parecer ya utilizado con el mismo fin durante la peste de $1582^{30}$. Su difusión y persistencia originó en 1601 el traslado de los enfermos a un espacio más amplio, también alejado del núcleo urbano, optándose por un conjunto de bodegas situadas en El Tinte, al final del Ejido, amplio espacio delimitado por la capilla de las Angustias y los conventos de Madre de Dios y franciscanos Descalzos, lo que indica la importancia ya de estas construcciones, con suficiente capacidad para acoger a un importante volumen de contagiados.

Ante el anuncio de la ocupación la reacción de los dueños de las bodegas no se hizo esperar, como tampoco la de algunos vecinos e incluso conventos cercanos. Uno de los primeros manifestantes, Gómez de Molina, destacaba el daño al comercio vinatero al expresar que en el Tinte ...esta recogido todo el vino o a lo menos la mayor parte del que en esta ciudad se carga para las indias..., como también la distribución de las bodegas, todas ellas ... en una ysla e incorporadas las unas con las otras e divididas con un solo tabique o tablas demas de lo qual no abra persona alguna que se atreba a visitar ninguna de las dichas bodegas $y$ ansi no se podrá beneficiar el vino $y$ conocidamente se perderá y no habrá salida

${ }^{29}$ CARMONA GARCÍA, Juan I: La peste en Sevilla. Sevilla: Ayuntamiento, 2004, pp. 203-273.

30 AMJF, AC, 1600. Fol. 134 vto. Se habla de dos mil personas contagiadas instaladas en el hospital de san Benito, lugar que abandonaron los carmelitas a cambio de otro sitio dado por la Ciudad.

${ }^{31}$ AMJF, AC, 1601. Fol. 156. del... ${ }^{31}$. Estas elocuentes palabras evidencian la importancia de este conjunto bodeguero en uso desde época anterior, cuya integración en un volumen apartado de la población permitiría una mayor comodidad en las labores vinícolas, reforzado por su ubicación, pues ...el dicho passo del tinte es la garganta desta ciudad y el mayor comercio de ella...

Del mismo modo se pronunciaron los herederos de Andrés Márquez de Omaña, propietarios de otras de las bodegas del conjunto, al expresar los malos vapores que el viento de Levante llevaría a los transeúntes, así como al público que asiduamente acudían a los cercanos conventos de Madre de Dios, Trinidad y Vera Cruz (el de Franciscanos Descalzos aún no estaba construido). El convento trinitario alegaba por su parte la celeridad en la propagación del contagio por el viento de Levante hacia los barrios aún no apestados, mientras se refería también a otros hospitales instalados en el año anterior en San Telmo y San Benito, el de este último susceptible de ser restaurado con la mitad de la cuantía que se habría de pagar por la ocupación de las bodegas del Tinte, mientras señalaba además: ... junto a dicho sitio de San Benito esta una bodega en que caben seiscientas camas y esta fuera del contagio de la ciudad.... ${ }^{32}$. Pero todos estos argumentos se diluían ante la extensión del contagio, de manera que el Cabildo decide instalar el hospital en estos inmuebles, desalojándolos de sus vinos y demás elementos, con división de enfermerías para hombres y mujeres, así como dependencias para el personal de asistencia ${ }^{33}$.

El conjunto bodeguero del Tinte volvió a ser protagonista en el nuevo brote pestífero

32 AMJF, AC, 1601. Fol. 159.

33 AMJF, AC, 1601. Fol. 166 vto.: La ciudad acordó de conformidad que se tomen todas la bodegas que fueren menester del tinte e se bazien luego e se echen fuera botas e pipas de vino que en ellas eviere para que se aga luego el ospital ... 
iniciado en diciembre de 1648 y extendido hasta 1650, con la instalación nuevamente del hospital, esta vez con especial protagonismo de la bodega más grande del conjunto, la denominada El Galeón ${ }^{34}$. La gravedad de las circunstancias obligaba a la rápida toma de los inmuebles, en muchos casos sin previa autorización de sus dueños. Conocemos algunos detalles al respecto gracias a las reclamaciones de los propietarios del pago por la ocupación, una vez pasada la epidemia. Como ejemplo, valga el testimonio de García López de Cabra, racionero de la catedral de Cádiz, quien reclama una retribución y expresaba el modo en que fueron ocupadas sus dos bodegas en los últimos días de diciembre de 1648: ...sin aberme avisado mandomela desocupar para el dicho efecto...me rrompieron con un acha una puerta que de la dicha bodega cae al patio del galeon y se Entraron en ella rrompiendo asimismo los candados de la puerta principal y me echaron fuera de ella ciento y treynta botas de vino que tenia en ellas con mas de sinquenta botas basias y demas peltrechos con que me obligaron a quitar dos bodegas...gaste en carretones y arrumbadores para conducir las botas y demas peltrechos a la bodega quatrocientos sesenta rreales... ${ }^{35}$.

Pese a la declaración del fin de la epidemia en octubre de 1649, hubo un rebrote en marzo del año siguiente, aunque solo duró hasta el mes de agosto, de manera que en septiembre de 1650 se acuerda entregar las bodegas que habían sido ocupadas por el hospital a sus correspondientes dueños, con los reparos necesarios $^{36}$. Sin embargo, este conjunto bodeguero no volvería a funcionar

${ }^{34} \mathrm{AMJF}, \mathrm{AC}, 1648$. Fol. 376vto.: ...an señalado en el tinte una bodega muy grande y capas que llaman el galeon en donde se pueden curar hombres y mujeres con separación... como para aposento de botica y enfermeria...

${ }^{35}$ AMJF, AC, 1650, fol. 188.

${ }^{36}$ AMJF, AC, 1650. Fol. 186 vto.

37 AMJF, AC, 1665. Fol. 448. La evolución de este conjunto del Tinte como cuarteles está en AROCA plenamente como lo había hecho hasta la primera instalación hospitalaria a causa de las ocupaciones y sus consecuencias, como también por la instalación del cementerio de los fallecidos por el contagio en sus inmediaciones. Las características de estos edificios, especialmente la bodega El Galeón, propiciaron también la ocupación para acuartelamiento de tropa en 1665 , algo que tomó carácter permanente ya durante todo el siglo XVIII ${ }^{37}$.

Como fórmula habitual, la primera medida preventiva en momentos de contagio era incomunicar la ciudad mediante el levantamiento de tapias, para evitar en la medida de lo posible el flujo de personas. También se restringía el comercio y suspendían las ferias, con incidencia directa en el movimiento vitivinícola. Así, iniciada la epidemia de 1600 el jurado Fernando de Torres tenía embarcadas 24 botas de vino con destino a las salinas de la Isla de León, aunque llegando a El Puerto de Santa María se ordenó el regreso, por lo que solicita al Cabildo el envío de una carta a la localidad vecina para la libre circulación de su cargamento ${ }^{38}$.

En 1649 se acuerda establecer un cordón sanitario y tapiar la ciudad, con accesos solo por la Puerta Nueva del Arroyo, calle Sevilla y el Tinte, a los que más tarde se incluía otro en la calle Pozo del Olivar, por ser ...el principal servicio de todos los cortijos y hasiendas... ${ }^{39}$. La situación de gravedad y extendido miedo al contagio nos podría llevar a pensar en la paralización total de las labores agroindustriales en la ciudad, pero aunque ciertamente hubo un lógico descenso, como consecuencia de la limitación comercial -a lo

VICENTI, Fernando: "Sobre arquitectura pública durante el siglo XVIII en Jerez". I Jornadas de Historia del Arte en Jerez de la Frontera. Arquitectura y diseño de la ciudad desde el siglo XVII hasta Isabel II. Asociación Jerezana Amigos del Archivo, Jerez, 2014, pp. 116-124.

${ }^{38}$ AMJF, AC, 1600. Fol. 746.

${ }^{39}$ AMJF, AC, 1649. Fol. 1221. 
que había que sumar también la crisis agraria generalizada en España entre 1647 y 1652-, la actividad vitivinícola no cesó. El movimiento durante la vendimia se hacía patente con un gran flujo de tráfico rodado hacia a las viñas, especialmente a mediodía y medianoche. Durante las epidemias, sin embargo, las tapias y puertas impedían con su cierre nocturno el libre tránsito, por lo que en 1650 se solicita al corregidor un régimen de apertura durante el día y la noche mientras se recogía la uva, lo que facilitaría además a los vendimiadores el libre tránsito a las haciendas, donde comenzaban sus labores al amanecer ${ }^{40}$. Todas estas cuestiones ratifican la importancia del desarrollo vitivinícola local, que como cabe observar llegó a hacer frente a los temidos males de contagio.

Junto a la quema de plantas olorosas -lentisco, laurel, romero, tomillo, etc. - y la cal, una de las medidas profilácticas más habituales durante las epidemias era el uso de vinagre para la desinfección. Empapar trapos para su posterior aplicación, rociar o sumergir en agua con vinagre ropa y objetos diversos eran recomendaciones habituales, como tantas veces aparece en la documentación. De esta forma la demanda del vinagre debió aumentar, aunque las abundantes reservas de las bodegas de la ciudad garantizaban su uso.

Pese a posteriores alertas por diferentes brotes surgidos en distintas ciudades, como Cartagena en 1677, Málaga, Antequera, Granada y Ronda en 1679, o El Puerto de Santa María en 1680, Jerez no volvió a padecer más contagios en este siglo.

${ }^{40}$ AMJF, AC, 1650. Fol. 185. Esta petición figura en el cabildo celebrado el 14 de septiembre.

41 Existen muchos contratos para transportar uva, aceituna, trigo, cebada, etc. Como ejemplo: APNJF, Diego Solís de Algeciras, 1682. Fol. 101: Francisco Silvestre y otros se obligan a traer a la ciudad, con

\section{Dos oficios unidos al vino: carreteros y toneleros}

Como en otras épocas, el desarrollo vitivinícola en el Jerez del Seiscientos no fue posible sin una serie de actividades complementarias, donde destacaron por su importancia los encargados del transporte de los caldos, así como los fabricantes de las vasijas en que eran depositados. El transporte, que se desarrollaba por vía terrestre y fluvial, abarcaba todo el desplazamiento del mosto desde las viñas a las bodegas de la ciudad, así como la posterior conducción del vino hasta el muelle del Portal, donde se embarcaban las botas y pipas que por el rio Guadalete llegaban a El Puerto de Santa María y Cádiz, desde donde partían vía marítima a los diferentes destinos.

Aunque existían lagares en algunas bodegas, la pisa de la uva se ejecutaba por lo común en los situados en las viñas, mientras que el envío del mosto se realizaba en botas o pipas cargadas en carretas. Cuando la uva se pisaba en la ciudad se solía transportar a lomos de caballos o jumentos, al igual que ocurría con la aceituna y cereales, aunque a veces también en carretas ${ }^{41}$. Todo ello justificaba la importancia de los carreteros, pues sobre todo en época de vendimia realizaban un incesante trabajo, que luego se veía ampliado con el transporte de la mercancía hacia el muelle del Portal en cualquier época del año. Como ocurre en la actualidad con el tráfico rodado, también los vehículos de tracción animal eran causantes de daños diversos, como los deterioros del empedrado -en aquellas calles que existía-, puertas mayores y postigos, así como en las casas, incluso muertes por atropello. Desde principios de siglo se habían establecido normativas para las carretas, basadas en una Real Orden dada

veinte caballos y cinco cuadrillas, toda la uva del diezmo del año. APNJF, Juan Gallardo de Huerta, 1674. Fol. 272: Manuel Rodríguez se obliga con Francisco Román a traerle con diez jumentos y dos machos toda la aceituna de su cosecha en pago de Macharnudo. 
en Madrid el 20 de agosto de 1614, donde se destacaba que sus ejes no debían sobrepasar las quince cuartas $^{42}$. Igualmente un bando dictado por el corregidor en 1621 recogía que ninguna persona podía estacionar en las calles ningún tipo de maderas, sombrajos ni carretas $^{43}$.

Los carreteros generalmente se establecen en lugares lo suficientemente espaciosos para poder alojar a sus animales y vehículos, lógicamente en las dos collaciones extramuros, San Miguel y Santiago, como demuestran los abundantes contratos para el transporte del mosto. De entre todos ellos destaca el Ejido, en la collación de San Miguel, que concentra al mayor número, repartidos entre la acera de Madre de Dios y la del convento de Los Descalzos y algunos tras la capilla de Las Angustias e incluso a espaldas del Tinte. Las estancias, ubicadas junto a sus viviendas, solían ser de madera y paja, materiales fácilmente inflamables, que en muchas ocasiones son sustituidas por piedra y cubierta de tejas ${ }^{44}$. También en el mismo barrio se localizan carreteros frente a San Agustín y calle Puerto. En el de Santiago la mayor concentración se registra en el callejón de Asta, seguido de la calle Lealas, Llano de San Sebastián y calles Sevilla, Pozo del Olivar, Molino del Judío, de la Sangre y Tierra de la Orden.

Para el acarreo de las botas las carretas eran tiradas por bueyes, animales de movimiento

${ }^{42}$ AMJF, sección Histórico Reservado, cajón 10, n. 24.

${ }^{43}$ AMJF, AC, 1621. Fol. 310.

44 En 1648 Alonso Meléndez, con vivienda en calle Campana y puerta trasera al Ejido, donde tenía sombrajo de madera y paja para estancia de bueyes, solicita licencia para sustituirlo por otro de piedra, madera y tejas tras su quema por haber prendido el fuego desde otros sombrajos vecinos, AMJF, AC, 1648. Fol. 352. Igualmente, Alonso y Blas Palomino, también en el Ejido, solicitan en 1679 licencia para sustituir sus estancias de madera y paja por otras de piedra y teja, con un informe del maestro mayor Diego Moreno Meléndez, quien señala que ha de ser ...dexando una calle por medio entre los más lento que la caballería pero más potentes en la tracción, en número de dos por vehículo (Figura 2), con varios viajes que incluían el traslado de las botas vacías de nuevo a las viñas. Muchos contratos reflejan el volumen a transportar, comprendido entre las dos a las cien botas; por el contrario en otros solo se habla de la traída del mosto del año, sin especificar el número de vasijas ${ }^{45}$. Aunque anterior a la época que tratamos, en la vista de Jerez plasmada por Wyngaerde se puede apreciar en un primer plano cierto movimiento de carretas (Figura 3), fenómeno habitual también en épocas posteriores.

El transporte de los caldos hasta el embarcadero del río, en El Portal, no era tarea fácil, pues el arrecife -que transcurría por las actuales barriadas y polígono industrial de la zona sur, hasta llegar al rio- presentaba un permanente estado de deterioro que afectaba seriamente a las carretas y ocasionaba en muchos casos la rotura de los recipientes con la consiguiente fuga de los caldos. En 1614 Tomas Quit y Diego Hal, mercaderes irlandeses, que junto a otros habían venido a la ciudad a comprar vinos para exportar fuera del reino, se quejaban de lo intransitable del camino, que impedía cargar más de una bota por carreta, pues el deterioro del terreno ocasionaba la rotura de muchas de ellas y

sombraxos y las casas de nuebe baras de hueco..., AMJF, AC, 1679. Fols. 577 y 588.

45 Entre los abundantísimos contratos de transporte localizados citamos dos ejemplos: en 1669 el carretero Bartolomé Sánchez se obliga con Vicente de Guzmán a traerle de sus viñas en Macharnudo cien botas de mosto, a precio de dos ducados el par, APNJF, 1669, Baltasar de Torres. Fol. 178. En 1624 el carretero Diego Hernández se obliga con Alonso Caballero de los Olivos, canónigo de la Colegial, a traerle ...todas las botas que procedieren de la heredad de viñas del pago de ducha que el susodicho tiene... de la cosecha deste presente año..., a 18 reales cada par de botas, APNJF, Cristóbal Rodríguez, 22 de septiembre de 1624. 
pérdida del líquido ${ }^{46}$. La continua insistencia da lugar a algunos arreglos en 1615 y otros al año siguiente; dos años más tarde se volvía a exigir por comerciantes locales y extranjeros una nueva intervención ${ }^{47}$. Pero realmente durante todo el siglo no cesaron las quejas por el mismo motivo, como reflejan las Actas Capitulares, lo que indica que a pesar de la importancia de esta vía para el comercio local nunca se procedió a una intervención adecuada ni a un nuevo trazado que facilitase un cómodo desplazamiento.

Actividad también clave para el desarrollo vinícola era la tonelería, cuyos envases requerían oficiales expertos para su ejecución, de forma que garantizasen la buena maduración y transporte de los vinos. De manos de los toneleros salían las principales vasijas utilizadas para las labores vitivinícolas, principalmente toneles, pipas, botas, barriles, tinas y tinetas, estas dos últimas comúnmente utilizadas para recibir el primer mosto tras la pisa. La configuración y caracteres de estos recipientes quedaron ya fijados en la ordenanza de toneleros de 1511, que completaban las ya aprobadas en 1482, donde se establecieron el tipo de madera, arcos, tamaño y capacidad, marcas, exámenes de los operarios, etc. ${ }^{48}$. La capacidad en arrobas (16 litros) era de 54 para los toneles, 30 para la bota y 27 para la pipa, mientras que de las maderas solo se expresa que han de ser de buena calidad y los arcos de sujeción de castaño, avellano o mimbre.

${ }^{46}$ AMJF, AC, 1614. Fol. 1563.

47 RÍOS MARTÍNEZ, Esperanza de Los: Antón Martín Calafate, pp. 60-68.

48 CARMONA RUIZ, María A. y MARTín GUTIÉRREZ, Emilio (eds.): Recopilación de las Ordenanzas del Concejo de Xerez de la Frontera. Siglos XV-XVI. Cádiz: Universidad, 2010, pp. 276-280. MARTíN GUTIÉRREZ, Emilio: Las bodegas en Jerez de la Frontera, p. 886.

${ }^{49}$ Contamos con numerosos contratos de compraventa de botas que, como en otros asuntos anteriormente
Durante el siglo XVII jerezano se mantuvieron básicamente todos estos caracteres, si bien contamos con referencias que nos permiten conocer más detalles de los recipientes utilizados y su configuración. Así, para las duelas aparece con frecuencia la madera de "Holanda" e "Irlanda" (no se especifica más), mientras que los arcos de sujeción se ejecutaban en castaño, avellano o mimbre ${ }^{49}$.

El empleo de arcos o flejes de hierro proporcionaban mayor solidez, pues su dureza y flexibilidad permitían una mejor unión de las duelas. Aunque no figuran en la mencionada ordenanza se utilizaron ya en el Quinientos, y en el siglo que nos ocupa debió extenderse más su uso a partir de la segunda mitad. En los contratos de compraventa e incluso inventario de bienes aparecen algunas referencias de estos arcos sobre todo aplicados a barriles ${ }^{50}$, aunque contamos con un documento de gran interés que demuestra su frecuente uso en la tonelería jerezana al menos desde finales de siglo. Se trata de una petición al Cabildo de un grupo de herreros gitanos a quienes, pese a tener acreditados sus exámenes de oficio, habían quitado las fraguas por su condición étnica. El hecho fue realmente tramado por el también herrero Francisco Rodríguez, que buscaba el beneficio tras el cierre de dichas fraguas para vender a precios más elevados sus productos. La reivindicación de los herreros está apoyada por un grupo de toneleros, que defienden la restitución de las fraguas clausuradas a sus dueños por estar solo tres de ellos capacitados para hacer los flejes o seguras de las botas,

tratados, harían interminables estas notas. Valgan como ejemplo la venta en 1648 de 20 cascos de botas nuevas...de madera de Holanda con arcos de castaño o abellano..., APNJF, Juan Gómez, 1648. Fol. 578. En 1652 el tonelero Tomas de Aquino vende a Juan Ramírez 20 botas nuevas ...de madera de olanda, arcaje de binbre afinadas y entarugadas con arcos de castaño..., APNJF, Antonio Cordero de Castro, 1652. Fol. 196.

50 APNJF, Francisco Ignacio de Magallanes, 1681. Fol. 54. En la partición de los bienes por muerte de Juan Muniel aparece un barril con arcos de hierro. 
pipas, toneles y tinas, de quienes se surtían no solamente los toneleros de la ciudad sino también los de El Puerto, Cádiz y Sanlúcar de Barrameda. El perjuicio, además, no solo afectaba a los recipientes empleados para el vino de Jerez, sino también a la pipas de la Chanca Real de El Puerto de Santa María ${ }^{51}$. Algunas de las aclaraciones de este documento nos pueden aportar la clave del posible escaso uso de las abrazaderas de hierro hasta el momento, donde destaca el hecho de que solo tres herreros figuren como capacitados para su ejecución, lo que explicaría, junto al coste del material, el encarecimiento de estas piezas frente a las de castaño, avellano o mimbre.

En cuanto a los instrumentos utilizados en la tonelería, la relación que aparece en un inventario de bienes nos puede ilustrar al respecto, figurando una plana de tonelero, una azuela, una segura de fondos, dos martillos, una bigornia, una jabladera, un rebote, una sierra, un compás un tirafondo y una segura vieja de labrar, junto a doce cascos de botas viejas y ocho nuevas ${ }^{52}$.

${ }^{51}$ AMJF, AC, 1695. Fol. 9 vto. Por su interés, creemos oportuno transcribir parte de este documento. Los herreros que firman la petición son los hermanos Francisco y Juan Monje, Sebastián Monje, Mateo Monje, Juan de Vargas Monje, Juan Enríquez, Nicolás de Los Reyes, Sebastián Jiménez, Francisco Rodríguez, Fernando Durán y Juan Moreno, quienes expresan: ...se nos han quitado las fraguas a pedimento de Francisco Rodriguez tambien herrero suponiendo que nosotros somos xitanos siendo yncierto por ser todos hijos y nietos y desendientes de castellanos viejos... y esto lo hace por estancar el oficio para vender su obra a precios eccesivos... Los toneleros Sebastián de Silva, Andrés Farfán, Andrés de Torres, Andrés Gómez y Sebastián de Aquino exponen las consecuencias del cierre de las fraguas, especialmente para la vinatería de la ciudad, ya que: ...las seguras y otras piezas de herramienta que tocan a nuestro exersisio de toneleros para la fabrica de las Botas toneles y pipas y tinas mayores sesara y se perderá la dicha vinatería que es muy grande en esta dicha ciudad y asimismo la fabrica de dichas pipas en la chanca Real que esta en la ciudad del puerto porque el dicho Alonso Ximenez y sus dos compañeros únicamente son los que saben
El uso de las botas ( 30 arrobas) y las pipas ( 27 arrobas) para la exportación también fue objeto de debate a principios de siglo al justificarse las ventajas de estas últimas por ser más ligeras y menos propicias al deterioro en el transporte que las primeras. Ante la disminución de las ventas como consecuencia de la predilección de los compradores de vinos envasados en pipas en otras localidades, los cosecheros y exportadores locales piden al Cabildo que se imponga su uso y fabricación ${ }^{53}$.

Como cabe observar, los toneleros constituían un notable grupo entre los menestrales de la ciudad, cuyo aprendizaje, como en el resto de los oficios, se llevaba a cabo mediante el ingreso en los talleres de los jóvenes aspirantes a oficiales y maestros. Así aparece en el nutrido conjunto de contratos de aprendizajes que hemos localizado, donde padres, tíos o simplemente tutores firman con el maestro tonelero las condiciones: tiempo de estancia en el taller -cuyo período solía oscilar entre los tres y seis años-, obligación de dar cama, comida, ropa y curar durante quince días si el aprendiz enfermase, etc. Por lo general, la edad de ingreso oscilaba entre

hacer las dichas piezas... porque no hay otras personas ni herreros que las sepan hacer $y$ particularmente las dichas piezas que llaman seguras.... Las autoridades deciden restituir las fraguas a los herreros perjudicados, argumentando: ... se les tiene en esta ciudad por naturales de padres y abuelos vezinos della aunque desiendan de castellanos nuevos no se les puede prohibir el uso y exersisio de quelesquier ofisios que quieran exerser... siendo como oy estan avencindados en esta dicha ciudad donde tienen sus vienes Rayces inmuebles mugeres hijos y familias y hombres muy quietos que estan como estan los mas dellos alistados por soldados de diferentes compañías de las milicias desta ciudad...

52 APNJF, Melchor de Mirabal y Molina, 1699. Fol. 29. El inventario pertenece a la partición de los bienes por fallecimiento de Sebastián de Aquino y Carrillo.

53 AMJF, AC, 1612. Fol. 1316. Este hecho ya fue señalado por SANCHO DE SOPRANIS, Hipólito y LASTRA Y TERRY, Juan de la: Historia de Jerez de la Frontera, pp. 3-4. 
los 11 y 16 años, aunque no faltaron algunos aprendices mayores de edad que directamente firmaban el contrato ${ }^{54}$. Una vez transcurrido el tiempo de enseñanza los aspirantes solían pasar a formar parte del taller como oficiales, sometiéndose a examen si deseaban abrir uno propio, tras cuya aprobación podían establecerse y recibir a su vez a oficiales y aprendices. Si por cualquier motivo no obtenían la licencia, era frecuente la solicitud de un permiso de apertura del taller durante seis meses hasta ser examinados ${ }^{55}$.

Entre los documentos consultados, aparecen también algunos casos de aprendizaje con maestros barrileros, bajo las mismas condiciones que los restantes ${ }^{56}$, posiblemente por tratarse de una especialidad dentro de la tonelería.

Los recipientes de tonelería eran vendidos bien por encargo o producidos para su posterior distribución en las ferias o por comerciantes particulares. En muchas ocasiones hallamos la compra de cascos de botas ya envinados, lo que facilitaría la labor para su uso vinícola, que generalmente figuran en la documentación como avinados o adobados $^{57}$. Las botas envinadas se vendían a precio algo más bajo que las nuevas, como se

${ }^{54} \mathrm{Al}$ respecto, recogemos el contrato establecido entre Pedro Rodríguez, natural de Braga y residente en Jerez, y el tonelero Domingo Martín, para ingresar como aprendiz en su taller durante seis años, APNJF, Francisco Arias Gallegos, 23 de diciembre de 1619. Igualmente Juan Gallegos firma su contrato de aprendizaje con el tonelero Antón Rodríguez Farfán, por tiempo de cuatro años y medio, APNJF, Pedro Camacho de Grajales, 19 de abril de 1621.

${ }^{55}$ AMJF, AC, 1620. Fol. 815vto. Juan de Ibáñez, oficial de tonelero, solicita licencia para usar su oficio con tienda y oficiales durante seis meses mientras se examina del oficio. La Ciudad acordó concederle la licencia para usar su oficio con tienda, oficiales y aprendices. En el mismo año aparece otro caso similar, en este caso a petición del tonelero Juan Rodríguez, obteniendo durante seis meses la licencia para abrir taller, fol. 1048. refleja en numerosas ocasiones, quizás ante el posible deterioro por el uso, teniendo en cuenta la utilización de flejes de castaño o avellano predominantes hasta al menos el último cuarto del siglo, que las hacían menos consistentes ${ }^{58}$.

\section{Las bodegas y el paisaje urbano}

El perfil urbano del Seiscientos jerezano no debió diferir mucho del plasmado por Anton Van der Wyngaerde tras su visita en 1567, en cuyos dibujos preparatorios así como en la vista final no es posible identificar bodegas. Para una primera aproximación al panorama constructivo vinícola las fuentes documentales nos permiten establecer unos primeros planteamientos de su desarrollo en la ciudad. Una ciudad que, pese a su riqueza y amplísimo término municipal, no dejaba de mostrar carencias en infraestructuras, con continuos fracasos en los intentos de conducción del agua potable (existían solo dos fuentes púbicas, apartadas del centro urbano, la de la Alcubilla y la de San Telmo), escasez de empedrados en las calles, cúmulo de basura, fallidos intentos de la nueva calzada y muelle

56 APNJF, Álvaro López de Santiago, 1664. Fol. 55. APNJF, José de Castro, 1693. Fol. 190.

57 Como ejemplo, en 1625 Juan Rodríguez de Toledo vende al escribano Juan de Castro ...treinta cascos de botas abinadas... a 20 reales de vellón cada uno, APNJF, Cristóbal Rodríguez, 8 de marzo de 1625. En 1659 Mateo Rendón compra a Francisco Martinez quatro cascos de bota adobados..., APNJF, Juan de Castro, 1659. Fol. 614. En la partición de los bienes por fallecimiento de Diego del Castillo, veinticuatro, figuran 127 cascos "abinados", a 30 reales cada uno, APNJF, Diego de Soto Guerrero, 1651. Fol. 281 vto.

58 Para ver la diferencia de precios, tomemos dos contratos de compra de botas realizados en 1620 , donde figuran 6 botas nuevas a 29 reales cada una y dos "abinadas" a 20 reales cada una; y por otra parte tres botas nuevas a 28 reales cada una y otras tres "abinadas" a 20 reales cada una, APNJF, Pedro Gómez de la Barrera, 1620. Fols, 2128 y 2147. 
de El Portal así como canalización entre el Guadalete y Guadalquivir, etc. ${ }^{59}$.

La población del intramuros se distribuía en un conjunto de estrechas calles de herencia medieval, mientras que el extramuros continuaba su crecimiento a través de los barrios de San Miguel y Santiago, con espacios amplios que permitían calles más rectas y ventiladas, así como el asentamiento de bodegas de dimensiones más grandes (Figura 4). Junto a la Puerta de Santiago y Puerta Real -antecediendo a los mencionados barrios- se situaban dos amplios espacios multifuncionales, el Arenalejo de Santiago y la plaza del Arenal. El primero acogía durante la Semana Santa la ceremonia del Descendimiento y Entierro de Cristo, así como la celebración de la feria de agosto; la plaza del Arenal crecía como zona utilitaria de mercado, espacio escénico de representaciones y coso de espectáculos ecuestres y taurinos, desempeñando funciones de plaza mayor aunque sin sus explícitos caracteres morfológicos. En 1683 se inauguró el edificio de la alhóndiga, que presidía uno de sus lados mayores junto al arco del Corregidor, mientras que un año más tarde se ejecutaba la nueva carnicería y matadero en las inmediaciones. En la cercana plaza de Escribanos, ya intramuros, junto a las Casas Capitulares y frente al templo patronal de San Dionisio, se asentaba la Cárcel Real, trasladada en 1678 desde la cercana calle del mismo nombre (posteriormente de la Princesa y hoy José Luís Díez), que como era habitual presentaba un inhóspito e insalubre estado donde malvivían los presos ${ }^{60}$. Escasos eran, pues, las construcciones de carácter público en la ciudad, como en tantas otras, donde los edificios religiosos destacaban en el medio urbano (conviviendo también con algunas casas y palacios relevantes), dando lugar al característico fenómeno del

\footnotetext{
59 Esto último, en RíOS MARTÍNEZ, Esperanza de Los: Antón Martín Calafate, pp. 56-74.

60 AROCA VICENTI, Fernando: "Sobre arquitectura pública", pp. 137-138.
}

urbanismo barroco español conocido como la ciudad convento.

Si para conocer la distribución de bodegas en la ciudad durante siglo XVIII contamos con elementos de inestimable ayuda, como el Catastro de Ensenada ${ }^{61}$, para el XVII resulta obligado recurrir a los contratos de compraventa, arrendamientos, construcciones o reparos de bodegas, que permiten un primer acercamiento, aun cuando no constituyan datos concluyentes. Las collaciones de intramuros presentan un menor grado de concentración, teniendo en cuenta el entramado de calles angostas, que limitaban el transporte de la mercancía. No obstante hallamos bodegas asentadas en cada una de ellas: San Salvador, San Dionisio, San Mateo, San Marcos, San Lucas y San Juan, por lo general medianas 0 pequeñas, habitualmente asociadas a las viviendas. Así, aparecen bodegas en las calles Arroyo, Benavente, Espíritu Santo, Jabonería, Chancillería, Carpintería, San Marcos, plaza Vargas, plaza de San Juan, Postigo de la Merced, Puerta de Rota, entre otras. Muchas de ellas pudieron ser estructuras persistentes de épocas anteriores reformadas, dado que los barrios extramuros brindaban mayores posibilidades para el desarrollo vinícola y sus construcciones de nueva planta. No aparece, por otra parte, ningún signo de rechazo por los párrocos de las collaciones donde se asientan estos inmuebles, como ocurrirá a partir del tercer tercio del siglo XVIII en que comienzan a sustituirse muchas viviendas por bodegas, principalmente en las de San Mateo y San Marcos, ocasionando reiteradas quejas de sus párrocos ante la pérdida de feligresía ${ }^{62}$.

En el aspecto morfológico tampoco las bodegas alteraron el tejido urbano, pues ni siquiera interfirieron en el desarrollo de la ciudad convento, consolidada durante toda la

\footnotetext{
${ }^{61}$ El Catastro de Ensenada nos permite incluso conocer su distribución por collaciones. AROCA VICENTI, Fernando: De la ciudad de Dios, pp. 28-34.

62 Ibid., pp.25-29.
} 
centuria. Si a finales del siglo XVIII se dieron los primeros pasos para la transformación de la ciudad convento a la ciudad bodega, cuyo pleno desarrollo se producirá durante el siglo XIX, el XVII será determinante en la configuración de la ciudad de Dios, donde conventos, iglesias, capillas, hornacinas y otros símbolos religiosos conformarán la esencia de la ciudad sacralizada ${ }^{63}$.

La ciudad convento seguía, por lo tanto, creciendo espiritual y físicamente, con la ampliación de los cenobios que a veces llegaban incluso a incorporar alguna bodega. Así ocurrió con el convento del Espíritu Santo, que en 1688 y ante el aumento de religiosas optan por la compra de unas casas situadas a sus espaldas para ampliarlo. Se incluía además una bodega adyacente al compás, propiedad del cenobio, que sería vendida a una monja de la comunidad para edificar su propia celda, bajo condición de no levantar las paredes de la bodega más allá de su caballete, con las ventanas necesarias y sus correspondientes rejas $^{64}$ (Figura 5). Se observa aquí un fenómeno a la inversa del que se producirá a lo largo de los siglos XIX y XX, en que algunas dependencias de este mismo convento fueron vendidas para la ampliación de las colindantes bodegas de la firma Domecq.

Pero sin duda el mayor desarrollo de la arquitectura bodeguera se localiza en los dos barrios extramuros, capaces de acoger por su amplitud estructuras de mayores dimensiones. En el de Santiago abundan en las calles de la Sangre, Juan de Torres, Merced, Nueva, Lealas, Muro y Juan del Cubo,

${ }^{63}$ AROCA VICENTI, Fernando: "El Jerez de Ignacio López. Apuntes sobre una ciudad sacralizada". En MORENO ARANA, José M: El escultor Ignacio López y su época (1658-1718). Jerez, 2018, pp. 111-160.

64 APNJF, Juan Álvarez del Castro, 1688. Fol. 337. Sor Inés María Bermúdez adquiere la bodega en propiedad para labrase su propia celda. Se indica que la bodega esta ...avaxo de las gradas que suben a la puerta de la calle que entra a el conpaz de dicho convento... El precio de venta se estableció en 3.500 reales de vellón.
Arenalejo, Porvera, Escuelas, Gaitán, Piernas (Guadalete), Sevilla, Llano de San Sebastián y San Juan de Dios. En algunos casos de ventas - arrendamientos se habla de bodegas grandes, sin alusión a medidas. El de San Miguel, por ser el más extenso de la ciudad, registra el mayor número, muchas de las cuales las localizamos en las calles Atarazanas, Molino del Judío (Zaragoza), Caracuel, Bizcocheros, Antona de Dios, Valientes, Doctrina, Larga, Santa María, Armas, Pescadería, Rastro, plaza Silos, Guarnidos, Bodegas, Honda, Ávila, San Francisco de Paula, Arcos, Fontana, Corredera, San Pablo, Levante, Évora, Higueras, Pedro Alonso, Caballeros, San Miguel, Santa Clara, Cruz Vieja, Molineros, Sol, Vicario, Corral de San Antón, Sancho Vizcaíno, Molino del Viento, Empedrada, Hoyanca, Mariñíguez, Campana, Santísima Trinidad, Granados y Ejido.

La identificación en esta última collación de zonas con marcado perfil bodeguero es posible teniendo en cuenta el número de las localizadas y sus características, incluyendo algunas de las llamadas "grandes". Podemos establecer así cuatro zonas de alta concentración vinatera: Las Atarazanas, calle Bodegas, calle San Francisco de Paula y el Ejido. En las Atarazanas, espacio que comprendía la actual plaza de San Andrés y calle Santa Rosa hasta la calle de la Cruz, debieron existir bodegas ya desde el siglo XVI, pues parece que en 1569 se instala un hospital para la peste ${ }^{65}$, posiblemente en alguna de ellas. Los numerosos contratos de arrendamientos $\mathrm{y}$ ventas recogen algunas bodegas grandes, reflejadas también en los

65 MUÑOZ Y GÓMEZ, Agustín: Noticia histórica de las Calles y Plazas de Jerez de la Frontera. Jerez, 1903, p.200. El autor sostiene que el nombre de Atarazanas pudo deberse a la ubicación de un depósito de armamento, del que derivaría su nombre. Por nuestra parte, nos inclinamos a pensar que tal denominación podría derivar de la proliferación de atarazanas, como también eran denominadas las bodegas. 
precios. Así, en 1672 Francisco Ramos Baños arrienda a Juan Moscardo una bodega en las Atarazanas ... que son de las tres la de enemedio..., durante tres años a precio de 300 reales cada uno de ellos; un año más tarde, Juan de Villavicencio arrienda a Andrés García de Rojas, presbítero, una bodega por precio de cien ducados, cantidad bastante elevada que indica que debía ser de grandes dimensiones; por último, para no alargar la lista, recogemos el arrendamiento que Nuño Fernández de Villavicencio hace al presbítero Juan Montero, vecino de Cádiz, de ...unas bodegas grandes que tengo y poseo mias en esta ciudad en las atarasanas..., durante cuatro años a precio de 800 reales de vellón al año ${ }^{66}$.

Frecuentemente citada en los documentos como "calle detrás de San Francisco", la calle Bodegas existía con tal denominación al menos desde $1574^{67}$, por lo que ya debían abundar estos inmuebles que originaron su nomenclatura. La documentación proporciona abundantes referencias a bodegas, algunas grandes con tres "cuerpos" $y$ otras con dos e incluso bodegas

66 APNJF, Roque Pérez de Ceballos, 1772. Fol. 179. APNJF, Francisco Márquez Rendón, 1673. Fol. 230. APNJF, Francisco Márquez Rendón, 1686. Fol. 467.

${ }^{67}$ MUÑOZ Y GÓMEZ, Agustín: Noticia histórica, p. 289.

68 En 1668 Juan Croquer traspasa al jurado Esteban Durante Rallón ...dos bodegas que están incorporadas la una con la otra con tres puertas a la calle... en linde por una parte con bodegas de Pedro Benites y por otra parte con bodega de martin de trigos..., APNJF, Roque Pérez de Ceballos, 1668. Fol. 125. En la ya mencionada partición de los bienes por muerte de Diego del Castillo, veinticuatro y alguacil mayor de rentas y alcabalas de la ciudad, aparecen 34 aranzadas de viña en el pago de Parpalana, con ocho lagares, así como ...unas bodegas que estan detras del convento de san Francisco las unas con tres cuerpos y las otras con dos..., apreciadas en albañilería en 23784 reales de vellón y en carpintería 7542 reales, además de las botas envinadas ya mencionadas, APNJF, Diego de Soto Guerrero, 1651. Fol. 269.

${ }^{69}$ APNJF, Francisco de Arias Gallegos, 8 de febrero de 1653. Cristóbal Pastrana, veinticuatro, arrienda al incorporadas unas a otras ${ }^{68}$, con presencia también de la del inmediato convento de la Vera $\mathrm{Cruz}^{69}$.

La calle San Francisco de Paula -que debía iniciarse en la hoy adyacente Arboledillaconformaba junto a la perpendicular de Ávila otro de los sectores bodegueros más destacados, cuya situación en uno de los extremos de la ciudad proporcionaba abundante espacio constructivo, muy cerca del camino hacia el arrecife que conducía al Portal. También aquí se hacen menciones a bodegas grandes y pequeñas, destacando, entre otras, el conjunto perteneciente a la capellanía que en San Miguel fundaron Leonor Benítez y Pedro Romano, con tres bodegas ${ }^{70}$. Todo este sector experimentó un proceso de crecimiento que se vería ya consolidado a finales del XVIII con la construcción del nuevo matadero, punto de partida para las nuevas ordenaciones del yermo espacio inmediato, fundamentalmente con bodegas ya en el siglo $X I X^{71}$.

Pero el sector bodeguero más singular fue el desarrollado en el Ejido y su entorno, que acogía a los inmuebles de mayores

presbítero Diego de Camas una bodega...detrás del convento de san Francisco en linde de bodegas del convento y frayles de la santa bera crus que son dos cuerpos de bodegas divididos...

70 En 1687 se arriendan dos bodegas de la mencionada capellanía, una grande y otra pequeña, APNJF, Francisco de Castro, 1687. Fol. 436. Un año más tarde se arrienda otra bodega de la misma capellanía, ...que es la que esta en el patio..., APNJF, Melchor Mirabal Molina, 1688. Fol. 96. Finalmente, en 1691 se arrienda otra bodega ...que es la del medio que dicha capellanía tiene en la calle san Francisco de Paula..., APNJF, Melchor Mirabal Molina, 1691. Fol. 137.

${ }^{71}$ AROCA VICENTI, Fernando: Arquitectura y Urbanismo en el Jerez del siglo XVIII. Jerez: Centro Universitario de Estudios Sociales, 2002, pp. 77-80. AROCA VICENTI, Fernando: "Licencias y obras particulares en la arquitectura y urbanismo del siglo XVIII jerezano". En PEREZ MULET, Fernando y AROCA VICENTI, Fernando: Nuevas aportaciones a la Historia del Arte en Jerez y su entorno. Cádiz: Universidad, pp. 187-203. 
dimensiones, germen de futuros procesos de ocupación. Como ya hemos adelantado se trata de un amplio espacio situado en el extremo sureste de la ciudad, delimitado por la capilla de Las Angustias y los conventos de Madre de Dios y Los Descalzos, estos dos últimos como ejes de articulación de las construcciones, pues muchas de ellas aparecen en la documentación situadas en la "acera de Madre de Dios" o "acera de Los Descalzos", mientras que en su interior se disponía un amplio espacio cuyo paulatino proceso de urbanización se desarrollará durante los dos siglos siguientes. En el extremo más oriental se ubicaba el llamado Tinte $^{72}$, conformado por un conjunto de bodegas donde destacaba la denominada El Galeón, de grandes dimensiones, que debieron ser construidas en la segunda mitad del siglo XVI, pues fueron ya ocupadas para hospital durante las epidemias de peste de 1601 y 1649. Como se ha referido, este conjunto bodeguero llegó a reunir la mayor parte de los caldos que se exportaban a la Indias, favorecido por su situación, en una zona amplia sin apenas construcciones adyacentes y en línea directa con el camino que conducía al muelle del Portal.

La situación y caracteres del Ejido quedan reflejados en un plano levantado en 1736, cuyo aspecto no debía ser diferente al de la época que estudiamos, ya que no se produjeron alteraciones sustanciales hasta la segunda mitad del XVIII. Trazado con motivo de una propuesta para erigir dos cuarteles de

72 El origen se sitúa en la construcción de una torre a finales del siglo XIII. GRANDALLANA Y ZAPATA, Luis: Monumentos de Jerez. Jerez, 1885, pp. 89-90. MUÑOZ Y GÓMEZ, Agustín: La torre de Abu-Yusufo Torrecilla del Tinte. Jerez, 1892.

73 ALADRO PRIETO, José M: “La colmatación del Ejido, siglos XVIII-XIX. Hacia la transformación de Jerez en ciudad-bodega". Revista de Historia de Jerez, 2007, n. 13, pp. 256-273. Con motivo del proyecto castrense fueron levantados dos planos que se conservan en el Archivo General de Simancas.

${ }^{74}$ AMJF, AC, 1640. Fol. 952. AMJF, AC, 1652. Fol. 547. caballería, finalmente no llevada a cabo ${ }^{73}$ (Figura 6), en él figuran las bodegas del Tinte (letra A), la capilla de Las Angustias (letra G) y los conventos de Madre de Dios (letra L) y Los Descalzos de San Diego (letra I), con la alameda en el espacio central (letra E). De la existencia de una alameda en la zona hay ya constancia desde antes de 1640, año en que se lleva a cabo una replantación con 44 álamos, posiblemente ubicada en ese mismo lugar. De igual modo las dos hileras de árboles que aparecen en el plano junto al convento Descalzo fueron plantadas por este en 1652, ante la demanda de los frailes para mitigar los rigores del verano en sus salidas, además de servir de exorno ${ }^{74}$.

Aunque el conjunto de bodegas del Tinte fue mermando su actividad a raíz de la ocupación hospitalaria, durante todo el siglo se registran contratos de compraventa o arrendamientos de algunas de ellas. De cualquier forma, el uso vinícola se interrumpirá ya a finales de siglo para acoger durante todo el XVIII a los cuarteles de caballería y no se restituirá hasta bien entrado el siglo XIX ${ }^{75}$.

Además del conjunto del Tinte, existían numerosas bodegas, principalmente distribuidas entre la acera de Madre de Dios y la de Los Descalzos, muchas de ellas asentadas en las inmediatas calles Mariñíguez, Marimanta y Campana, algunas con puertas traseras directas al Ejido, así como otras situadas detrás del segundo convento y también junto al de La Trinidad ${ }^{76}$. Adyacente al de Los Descalzos se erigían igualmente las

75 AROCA VICENTI, Fernando: "Sobre arquitectura pública", pp. 116-124. ALADRO PRIETO, José M: La construcción de la Ciudad Bodega, pp.674-702.

76 Como muestras, en la partición de los Bienes por muerte de Alonso Ramos Franco figuran casas con bodegas accesorias en el Ejido, esquina a calle Marimanta, así como otra casa con bodega y corral con puertas a la calle Campana y la de la bodega al Ejido. APNJF, Diego de Soto Guerrero, 1663. Fol. 167. Por otra parte, Agustín Vela arrienda a Juan Barba una bodega detrás del convento de Los Descalzos, APNJF, Baltasar de Torres, 1665. Fol. 281. 
bodegas del Diezmo, como veremos en el apartado siguiente.

Como ya señalamos, el Ejido daba cabida también a numerosos carreteros con sus viviendas y estancias para bueyes y carretas. Construcciones igualmente presentes eran los silos, pues hay constancia documental de la existencia de algunos, como asimismo el molino de aceite que figura en el plano antes mencionado (letra C), levantado en $1678^{77}$. De esta forma se hacían presentes en este sector expansivo de la collación de San Miguel la tríada de productos agrícolas mediterráneos, con la clara supremacía del vino. No debemos olvidar, al respecto, la situación de esta zona en uno de los extremos de la ciudad, de forma que los cultivos de viña y olivar se iniciaban a escasa distancia de las bodegas del Tinte.

A propósito de esto último, conviene insistir en el manifiesto predominio del cultivo de la vid sobre el olivo, cada vez más mermado, que tuvo su respuesta en la proliferación de bodegas por toda la ciudad en detrimento de las almazaras, localizadas en menor medida. De esta forma es constatable la supremacía de contratos bodegueros frente a los de molinos aceiteros.

\section{La bodega del siglo XVII jerezano}

Cabría plantear inicialmente si todas las bodegas que aparecen en la documentación fueron realmente espacios vinícolas, ya que el término podría aludir también a inmuebles para almacenaje de otros productos. Las mismas fuentes nos aportan las claves para identificar a estas construcciones como espacio dedicado al vino, pues en algunas

77 En 1628 Francisco Camacho Gallo solicita licencia para hacer seis silos en el Ejido ...junto a los que allí tiene el licenciado Garcia Fernandez de Cuellar presbitero..., AMJF, AC, 1628. Fol. 1156. El molino fue levantado por el veinticuatro de la ciudad Esteban Martínez de Ortega, AMJF, AC, 1678. Fol. 924 vto.

78 APNJF, Juan de Castro, 1659. Fol. 3. APNJF, Alonso Rivera Zapata, 1696. Fol. 39. APNJF, Francisco Márquez Rendón, 1696. Fol. 1119. ocasiones al ser arrendadas para otros usos son expresamente referidos en las condiciones de los contratos de arrendamiento. Valgan como ejemplos la bodega que en 1659 arrienda María de Montalvo dentro de su casa en calle Pedro Alonso a Sebastián de la Barrera, para ...enserrar en ella paxa de senteno..., o la que en 1696 arrienda Pedro del Castillo a Francisco Muñoz en la calle Armas para guardar maderas, y en el mismo año Antonio Gómez a Pedro Martín ...una bodega que a servido de almasen de madera..., en calle Pozo del Olivar $^{78}$. Por su abundancia y caracteres estos inmuebles proporcionaban, por lo tanto, una socorrida ayuda para múltiples usos, como ya veíamos con los hospitales durante las epidemias o el cuartel de caballería, también alguna arrendada para hospicio e incluso para la alhóndiga mientras se construía su nuevo edificio $^{79}$. Aun así, debemos insistir en la prevalencia del uso original, ya que el grano y otros productos como el aceite eran depositados en silos, graneros o almacenes, estos dos últimos por lo general situados en la parte alta de las viviendas para así evitar la humedad y acceso de roedores.

No sabemos a ciencia cierta si se conservan algunas bodegas del Seiscientos en la ciudad, principalmente por dos motivos, por una parte la gran proliferación de las de nueva planta levantadas durante el siglo XVIII, que en muchos casos pudieron reemplazar a algunas anteriores o bien reformarlas, y por otra su difícil identificación, habida cuenta la reiteración de los modelos ya empleados desde el siglo $\left.X V\right|^{80}$, inalterables hasta el XX en que las nuevas técnicas y materiales permiten

79 Esteban Bermúdez, vecino de Antequera, arrienda a la Hermandad de la Santa Caridad una bodega en la calle Armas para hospicio de los pobres, durante dos años, bajo la condición siguiente: ... se a de adobar y rreparar la dicha bodega de todo lo nesesario de forma que la pueda abitar..., APNJF, José de castro, 1689. Fol. 128.

80 GUERRERO VEGA, José M. y ROMERO BEJARANO, Manuel: "The origins of the wine", pp. 1441-1454. 
diversificar las plantas y alzados. Las fuentes documentales recogen los dos modelos más habituales también desarrollados en la siguiente centuria: la bodega asociada a la vivienda y la independiente, por lo general de mayores dimensiones. Las incluidas en las viviendas solían estar o bien adyacentes, comunicadas mediante patios, corrales 0 simples puertas, o bien situadas dentro de las viviendas, tanto en zaguanes como junto a patios o galerías. Así, en el anteriormente mencionado arrendamiento de bodega en calle Pedro Alonso se aclara su situación: ...por donde se ba al segundo patio de las dichas casas... Frecuentes eran también las bodegas con graneros en el piso superior, tanto las asociadas a las viviendas como otras exentas, algunas de las cuales las localizamos en las calles Higueras, Pescadería, Molineros, Lealas, Antona de Dios, plaza de San Miguel, Santa Clara, Caballeros y Doctrina ${ }^{81}$. Las bodegas con almacenes debieron incluir cubiertas abovedadas en la planta baja y de vigas de madera y ladrillo con teja exterior en la parte superior, tal y como se desarrollarán en la siguiente centuria ${ }^{82}$. Aparecen también ciertas referencias a la capacidad de algunas de las incorporadas a las viviendas, como la que en 1648 arrienda Francisca de Vera, en el patio de su casa, a Alvaro Nuñez Cabeza de Vaca, para cuarenta botas ${ }^{83}$. De cualquier manera, el número de botas de mosto

${ }^{81}$ Recogemos solo algunos ejemplos. En 1661 Catalina Jiménez arrienda a Juan Manzanares un almacén alto y una bodega que hay debajo en sus casas de la calle Molineros, APNJF, Juan Caballero de Sanabria, 1661. Fol. 375. En la partición de los bienes por muerte de Francisco del Salto figuran una bodega con pajar encima en sus casas de calle Lealas, APNJF, Juan Gómez Rendón, 1661. Fol. 294. En 1674 Fernando de Zurita y Haro, veinticuatro, arrienda a Pedro Espínola ...unos almacenes altos y una bodega debajo dellos...detrás de las casas principales de su morada callejuela que llaman de Don Gomez..., APNJF, Juan Caballero de Sanabria, 1674. Fol. 166. En 1681 Sebastiana de Herrera arrienda a Jerónimo de Cáceres ...una bodega con un almasen ensima y en la dicha bodega una cavallerisa... en la calle molineros..., APNJF, Juan López Moreno, 1681. Fol. 138. transportado desde las viñas que hemos citado nos puede dar una idea de la capacidad de las bodegas receptoras, según las cantidades señaladas.

Las bodegas independientes presentan los modelos más característicos y frecuentes tal y como se desarrollan desde el siglo XVI e incluso épocas anteriores: plantas rectangulares con una, dos o más naves cubiertas con techumbre de ladrillo por tabla y vigas de madera, a dos aguas, sustentadas por pilares con arquería (o sin ella) y teja en canal y redoblón al exterior. Solían ser de mayor capacidad y autonomía para las labores vinícolas, aunque no faltaban las de pequeñas dimensiones, de las que poseemos alguna referencia, como una situada en la calle Caracuel, de nueve varas de largo y tres y poco más de ancho ${ }^{84}$. En un informe de 1656 sobre una bodega arruinada en la calle Escuelas, los alarifes Juan Pérez de la Parra y Antonio Domínguez, junto al maestro mayor Antón Martín Calafate, expresaban: ...la dicha bodega esta al presente caido todo el techo della y solo tiene sus sercas y dos paredes en medio la una de Dança de Arco y la otra pared masisa con sus puertas... ${ }^{85}$, como también la venta de una bodega en 1695 aclaraba la inclusión de dos naves con pilares de cantería y dos puertas ${ }^{86}$. En la partición de los bienes por muerte de Esteban Rallón y su esposa, Ana

82 AROCA VICENTI, Fernando: De la ciudad de Dios, pp. 104-110.

${ }^{83}$ APNJF, Miguel Vázquez Palazuelos, 1648. Fol. 915.

${ }^{84}$ Estas son las medidas de la bodega que Francisco de Mendoza vende a Baltasar de Torres en la mencionada calle Caracuel, en linde con bodegas de Diego de Padilla. Dichas medidas corresponderían a unos ocho metros de largo y tres de ancho, APNJF, Andrés de medina Astorga, 1692. Fol. 84.

$85 \mathrm{El}$ informe figura en un expediente de 1684 sobre la administración de bienes, APNJF, Juan Gómez Rendón, 1684. Fol. 131.

86 APNJF, Lorenzo Meléndez, 1695. Fol. 585. El inmueble estaba situado en la calle Bueltas de la Alcobilla 
Duque, fechado ya en 1705, figuran por una parte una bodega grande de tres naves ...con el servicio ordinario de poço poça y patio...en calle Bodegas tras el convento de la Vera Cruz, a la que se suman ...otras Bodegas chicas en el sitio donde esta la taberna el quarto alto y la sala baja cocina y trasmano con todo el servicio ordinario de Poço y Poça que esta contiguo a las dichas bodegas grandes y por otro lado el dicho convento de la Bera cruz... ${ }^{87}$. En otros casos se habla de patios con pozo para el uso, bien individuales o bien para compartir con otras estructuras.

La mención a la taberna resulta de interés, pues junto a las bodegas chicas se menciona a una como lugar habitual para la venta y consumo local del vino, por lo que se pudo generalizar su ubicación junto a ellas para facilitar así el despacho de los caldos. El término bodegón aparece también frecuentemente citado para el mismo fin, $y$ junto con la taberna se diferenciaban de los mesones y posadas en que estos últimos ofrecían hospedaje. Un bando dictado por el corregidor en 1621 ordenaba que ni taberneros ni bodegoneros podían suministrar comida a hombres casados ni vecinos de la ciudad, como también que ambos evitasen dar de comer a persona alguna en los días de fiesta antes de la misa mayor. Del mismo modo que ningún tabernero ni bodegonero tuviesen camas de alquiler, lo que aclara la diferencia con los mesones y posadas, que sí ofrecían alojamiento. Por último se incluye también: ... que los bodegoneros, mesoneros ni benteros tengan a su servicio mujeres de mal vivir que ganen con sus cuerpos pena de cien azotes...88.

Pero las bodegas de las que poseemos descripciones más detalladas son las del Diezmo, dentro del conjunto de la antigua cilla

${ }^{87}$ APNJF, Andrés Medina Astorga, 1705. Fol. 578. Pese a que la fecha de partición de los bienes entra ya en el siglo XVIII, las bodegas citadas debieron ser construcciones anteriores.

${ }^{88}$ AMJF. AC, 1621. Fol. 310. ubicada junto al convento de Los Descalzos sobre unas antiguas compradas a Jerónimo de Figueroa, insertas en un informe del arquitecto Pedro Sánchez Falconete de 1629, que incluye planos de la reforma por el alarife jerezano Antón Martín Calafate ${ }^{89}$. El conjunto estaba formado por de tres bodegas, una de dos naves con 53 varas de largo y 12 varas de ancho en cada nave, además de siete arcos y tres puertas a la calle, con capacidad para 500 botas, cuyo tejado tenía que ser reconstruido; otra, con una nave de 6 varas de ancho y 35 de largo tenía capacidad para 180 botas; y una tercera con otra nave más de 38 varas de largo y 5 de ancho. Dos de estas presentaban sus cuerpos sin cubierta, por lo que habían de cubrirse, además de la ejecución de dos corredores abiertos para alojar lagares.

En el nuevo proyecto (que no llegó a ejecutarse) se disponían en torno a un patio ocho bodegas, una con capacidad para 210 botas, dos con capacidad para 200 y tres para 180 botas, unidas a seis almacenes para granos, que aumentarían hasta nueve al tener tres de ellos dos plantas, tal y como figura en el plano (Figura 7). En el material gráfico también aparece un plano de la bodega $\mathrm{El}$ Galeón (Figura 8), ubicada en el cercano conjunto del Tinte, de 56 por 22,6 varas de cuatro naves y pilares, con capacidad para 1500 botas, cuya inclusión podría responder a una posible opción de compra para incorporar al proyecto, finalmente no llevada a cabo, ya que fue utilizada como hospital durante la peste de 1649.

Tenemos constancia documental de las principales obras desarrolladas en esta nueva cilla del arzobispado sevillano, en uso hasta su traslado al nuevo conjunto en la calle Porvera

89 LUNA FERNÁNDEZ ARAMBURU, Rocío y SERRANO BARBERÁN, Concepción: Planos y dibujos del Archivo de la Catedral de Sevilla. Sevilla: Diputación Provincial, 1986, pp. 194-195. ROMERO BEJARANO, Manuel y GERRERO VEGA, José M: "The origins of the wine", pp. 1441-1454. 
en $1788^{90}$, lo que verifica definitivamente que el mencionado proyecto integral no se llevó a cabo. Así, en 1629 el maestro Antón Martín Calafate se obliga con el Cabildo de la Santa Iglesia de Sevilla a realizar obras en las bodegas...donde se a de recoger los diesmos de uba que estan en esta ciudad linde del convento de los descalsos que compraron a don geronimo de Figueroa...91. Se compromete a realizar una puerta a la calle de cantería, con su tejado que buele por dentro y fuera..., y delante de la bodega ya hecha un corredor sobre pilares de piedra, de cinco varas de ancho, techado con canes de madera y tejado cubierto con canalón, con buenas mezclas de cal y arena; también aclara: ...que la bodega que oy esta enfrente de la puerta principal que corre hasta la bodega grande desde la pared de los frailes y se a de cubrir para ello se a de enrafar la pared...se pueda cargar el enmaderado... y se a de texar esta dicha bodega y Portal de canelón y Doblon y mescla de cal y arena Revocado... La propia cilla se haría cargo de los materiales necesarios (piedra, ladrillo, cal, yeso y arena), así como de las herramientas, sogas, espuertas y demás enseres. El precio estipulado por Martín Calafate fue de 1700 reales de vellón. El mismo documento recoge los trabajos del maestro carpintero Bartolomé Sánchez de la Fuente en el mencionado corredor, donde se asentarían cincuenta vigas, así como en las puertas y demás.

Un año más tarde el mismo Martín Calafate se compromete a cubrir una de las bodegas destechadas y a realizar dos arcos para el cocedero de mosto, así como un nuevo corredor delante de ella, siguiendo el modelo de los ya ejecutados, como también a

90 SERRANO PINTEÑO, Javier: "Un edificio del siglo XVIII en Jerez: la Casa de los Diezmos", Revista de Historia de Jerez, 2001, n.7, pp. 77-82.

${ }^{91}$ AMNJF, Juan de Ocaña, 1629. Fol. 611-615. Agradezco al investigador Jesús Antón Portillo el haberme facilitado la localización de este documento, así como los de las dos notas siguientes. ejecutar ...otro cuerpo de bodega que a de correr desde el dicho cocedero a la pared de la calle de la plaça del exido arrimado a un corral de dicho monasterio... y hare una portada de canteria en medio del cuerpo de la dicha bodega y cubrirla de canelón..., todo conforme a la planta que tenia entregada y un presupuesto de 2700 reales de vellón. Bartolomé Sánchez de nuevo se encarga de los trabajos de carpintería de ambas bodegas con techumbres a dos aguas ${ }^{92}$. Las obras continuaron al año siguiente por el mismo Martín Calafate en la bodega grande con una nueva cubierta, así como el reparo de las paredes donde se asentarían las cabezas de las vigas, con un presupuesto de 950 reales $^{93}$. Una última intervención tuvo lugar en 1635 por el albañil Juan Camacho, destinada al reparo de todos los tejados de las bodegas y portales ${ }^{94}$.

La existencia de lagares en estas bodegas estaba justificada por la recepción cada año del diezmo de la uva (ya veíamos en el apartado del transporte de los caldos algún ejemplo de la traída de la uva del diezmo, recogido en la nota 41), donde además del vino debió producirse abundante arrope en el cocedero de mosto.

Tampoco sabemos con certeza si eran estas las únicas instalaciones diezmales del arzobispado, pues en un documento de 1637 se habla de una huerta lindante a las bodegas del diezmo en las Atarazanas, que bien podían haber servido para tal fin antes de la ejecución de las nuevas o compatibilizar ambas el mismo uso ${ }^{95}$.

De este conjunto de bodegas nada queda actualmente, aunque en parte del recinto en

\footnotetext{
92 APNJF, Francisco Álvarez, 1630. Fol. 396 vto. y 399.

93 APNJF, Francisco Álvarez, 1631. Fol. 825 vto.

${ }^{94}$ APNJF, Francisco Álvarez, 1635. Fol. 563 vto.

${ }^{95}$ AMJF, AC, 1637. Fol. 1231. Pedro González manifiesta tener tres aranzadas de tierra que...en otro tiempo era la huerta de quemada linde por una parte las bodegas del diesmo en las atarazanas...
} 
el que estuvieron ubicadas es posible identificar algunos elementos de la época, como una estancia cubierta con vigas labradas -posiblemente granero- (Figuras 9 y 10), así como una escalera con peldaños y barandal de madera, no sabemos si pertenecientes al conjunto de la antigua cilla o al colindante convento Descalzo (Figuras 11, 12 y 13).

Pero no eran solo estas las bodegas en poder del estamento eclesiástico, pues la mayoría de los conventos, principalmente los masculinos, eran dueños de algunas, como también de viñedos. Algunos de ellos poseían varias, situadas tanto dentro de sus recintos como en otras zonas de la ciudad, muchas de las cuales eran cedidas en régimen de alquiler. Así, los frailes de la Victoria tenían además de la de su convento otras en las calles Lealas y Juan de Torres, y viñas en el pago de Espartinas ${ }^{96}$, como igualmente el de Santo Domingo, que además de las conventuales ${ }^{97}$ poseía otra en una casa de la calle Gaitán ${ }^{98}$. La bodega del convento dominico debió ser importante por su capacidad y producción, pues de nuevo el cronista de la época Sebastián Marocho escribe en 1662: Este año salió la procesión del Corpus la dominica infraoctava de Santo Domingo; hubo arcos triunfales, ricos altares y una fuente de vino en el rincón de la Portería del más exquisito que había en la bodega ${ }^{99}$. El convento de San Juan de Dios poseía al menos dos bodegas, una de ellas grande junto a sus dependencias, una de las cuales pudo ser la

${ }^{96}$ APNJF, Juan Gómez Rendón, 1650. Fol. 85; 1659. Fol. 476; y 1660. Fol. 87.

${ }^{97}$ GUERRERO VEGA, José Mā. y ROMERO BEJARANO, Manuel: "Datos para la historia de la arquitectura del vino en Jerez de la Frontera. El caso de la bodega-iglesia del convento de Santo Domingo". En HUERTA, Santiago y LÓPEZ, Fabián (eds.) Actas del Octavo Congreso Nacional de la Construcción. Madrid: Instituto Juan de Herrera, 2013, pp. 445463.

98 APNJF, Pedro Camacho Grajales, 22 de marzo de 1651.

99 MAROCHO, Sebastián: Cosas notables, p. 23.

100 APNJF, Juan de Ocaña, 1642. Fol. 410 vto. No aparecen en este contrato referencias a medidas ni construida por los maestros albañiles Juan Benítez y Benito Martín en $1642^{100}$. Por su parte los jesuitas tenían bodega en las Atarazanas, así como los cartujos en las calles Naranjas y Doctrina, y los mercedarios calzados frente al convento de san Cristóbal en una casa ${ }^{101}$. En algunos documentos citados se habla también de la bodega del convento de la Vera Cruz (ver nota 69). Conocemos asimismo la existencia de algunas del convento de la Santísima Trinidad, tanto en su recinto como en la calle del mismo nombre, como debía ocurrir con el de San Agustín, poseedor también de viñas ${ }^{102}$.

En los monasterios y conventos en general las bodegas se destinaban principalmente al consumo interno, con especial dedicación a los vinos para consagrar. Sin embargo en Jerez, mediante los arrendamientos y otras operaciones, constituían además importantes fuentes de ingresos a las comunidades, a las que a veces también se realizaban donaciones de vino para consagrar, como así figura en partición de los bienes por fallecimiento de Elvira Núñez, donde aparecen tres botas de vino que se dieron para misas, una al convento de San Francisco y dos al de la Vera Cruz ${ }^{103}$.

Tal y como hemos comprobado, las plantas y alzados de las bodegas del XVII jerezano no difieren de las proyectadas en los siglos antecedente y siguientes, por lo que no creemos necesario detenernos más en este

a caracteres de la obra. También aparece otra bodega propiedad del convento en APNJF, Juan Gallardo de Huertas, 1669. Fol. 244.

101 APNJF, Francisco Arias Gallegos, 6 de abril de 1652. APNJF, Juan Gallardo de Huertas, 1670. Fol. 42. APNJF, Pedro Gómez de la Barrera, 1621. Fol. 209.

102 APNJF, Juan de Castro, 1652. Fol. 720. José de Castro, 1682. Fol. 532. Sabemos que el de San Agustín poseía viñas en los pagos de Carrascal, Burujena y Las Doncellas, según contrato con el carretero Blas Palomino para transportar el mosto ...a las bodegas que se señalaren en esta ciudad..., APNJF, Juan López Moreno, 1699. Fol. 446.

103 APNJF, Gómez de Trujillo, 1664. Fol. 492. 
aspecto. Igualmente las obras fueron ejecutadas tanto por maestros mayores como por albañiles, quienes también realizan aprecios y tasaciones. Ya hemos visto las intervenciones de Antón Martín Calafate, maestro mayor de la ciudad y figura más destacada de la arquitectura de la primera mitad de siglo tanto en Jerez como en otras ciudades cercanas, al que sucede Diego Moreno Meléndez, que también realizó tasaciones y con toda probabilidad algunas bodegas de las que aún no tenemos constancia documental ${ }^{104}$. Junto a ellos localizamos a otros maestros albañiles, como Pedro Rodríguez del Raño, Diego de Castilla, Diego Beato de Rojas, Antón Martín de Burgos $^{105}$, Juan Camacho, Juan Benítez, Benito Martín, Juan Pérez de la Parra, Antonio Domínguez o Nicolás Gutiérrez Amarillo ${ }^{106}$.

\section{Conclusiones}

Quizás la prevalente idea de crisis tradicionalmente transmitida por el Seiscientos en general haya llevado a pensar en un escaso desarrollo de la vitivinicultura local. Si bien es cierto que no se desarrolló el movimiento vinícola del dorado siglo XVI, ni las bases dieciochescas que llevarían al definitivo lanzamiento del jerez como el caldo más internacional, hecho ya consolidado en el siglo XIX, no podemos hablar de un siglo XVII aciago para el vino, habida cuenta la abundante información que el exhaustivo -y aún inacabado- rastreo por los archivos nos ha proporcionado. Considerando esto último, no está aquí expuesta toda la información que poseemos tras las consultas de las Actas Capitulares y Protocolos Notariales, que por

104 Los citados maestros mayores en RíOS MARTíNEZ, Esperanza de Los: Antón Martín Calafate, pp. 181296. El aprecio por Moreno Meléndez de un solar ruinoso que fue bodega en el Tinte, en Ríos MARTíNEZ, Esperanza de Los: “Aprecios, Tasaciones y particiones de casas de Antón Martín Calafate y Diego Moreno Meléndez". Atrio, n. 8-9. Sevilla, 1996, pp. 253-239. En 1695 Moreno Meléndez aprecia igualmente casas y bodegas, APNJF, Lorenzo Meléndez, 1695. Fol. 269. cuestiones de espacio hemos tenido que limitar. Quedarán para futuros trabajos.

Pese a los períodos de crisis y adversidades, se cultivaron viñas, tanto en manos de propietarios de distintos estamentos sociales como de arrendatarios, y se elaboró el vino para un comercio sobre el que recaía unos de los principales pilares de la economía local; y nada de esto fue posible sin el levantamiento de bodegas: pequeñas, medianas y de grandes dimensiones, asociadas a las viviendas o independientes. Todo ello hacía de Jerez una ciudad vinícola, cuyo máximo movimiento, en época de vendimias, no fue alterado ni siquiera por acontecimientos tan adversos como las epidemias de peste.

La amplia red de bodegas extendida por toda la ciudad fue un hecho, aunque los dos barrios extramuros, Santiago y San Miguel, por cuestiones de espacio, albergaron el mayor número, con sectores de alta concentración, algunos especialmente peculiares como el Ejido, que ya desde el siglo XVI planteaba sólidas bases para su evolución como expansiva zona industrial. Pese a todo, aún quedaba lejos la metamorfosis de la ciudad convento en ciudad bodega, pues el protagonismo de la arquitectura y demás símbolos religiosos se encargaban de recordar a los fieles que habitaban en la ciudad de Dios. La importancia de la industria vinatera para el desarrollo económico local -frecuentemente reflejada en la documentación como justificación de reivindicaciones diversasquedaba en parte limitada por el proteccionismo que la caracterizó, en manos de una sociedad de marcado carácter religioso, no suficientemente consciente de su

105 Estos albañiles aparecen como apreciadores para la subasta de la bodega de Andrés Márquez de Omaña, en el Tinte, donde estuvo el hospital, APNJF, Francisco Arias Gallegos, 17 de junio de 1620.

106 Este último se compromete en 1615 a repararle a Francisco Caballero de los Olivos una bodega en la calle Bodegas, APNJF, Lorenzo Arias Gallegos, 20 de septiembre de 1615 . 
proyección. Muchos de los hacendados, cosecheros y vinateros locales extendieron ese proteccionismo al plano espiritual, hasta invertir más en la salvación de sus almas que en sus propios negocios:

...mando que se vendan mis vinos que yo tengo e se digan de misas todo el precio dellos en santo Domingo y guía y san miguel...mando que el esquilmo de mis viñas que al presente Esta en ellas pendiente se venda y de lo procedido de ello se digan de misas resadas por mi anima y de mis padres $E$ difuntos $y$ personas a quienes puede ser Encargo en la yglecia e monasterios que mis albaceas paresiere... ${ }^{107}$.

\section{Anexo}

Figura 1. Partición de los bienes que quedaron por fallecimiento del jurado Antonio Bermúdez. 1650



${ }^{107}$ Así lo dejó escrito el jurado Alonso Muñoz de Jara en su testamento en 1602 (inserto en un documento de finales de siglo), a raíz de la partición de sus bienes, donde figuran también casas y bodegas en calle Larga, APNJF, Lorenzo Meléndez, 1694. Fol. 79. En los testamentos y particiones de bienes de la época figuran el número de misas encargadas por el difunto, que aumentaban según el poder adquisitivo desde las 30-50 de las personas menos acaudaladas hasta las mil o dos mil misas de las más pudientes. En algunos casos volvemos a encontrar
Figura 2. Bodega en Jerez. Dibujo y litografía de E. Parkinson. S. XIX

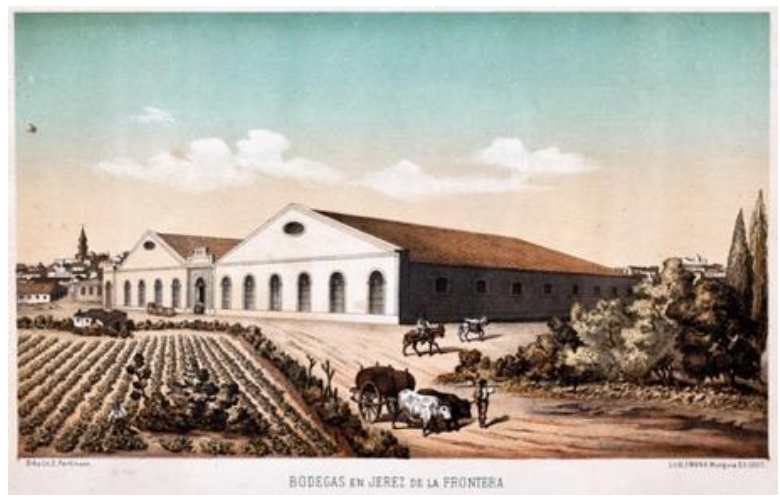

Figura 3. Anton Van der Wyngaerde. Jerez de la Frontera. 1567

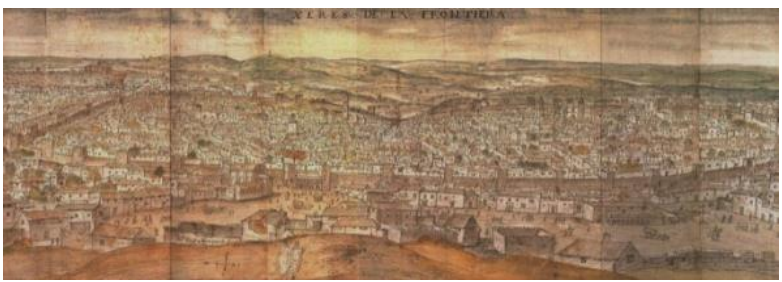

Figura 4. Plano de Jerez de la Frontera. Francisco Javier Velázquez, 1825. A la derecha, en tono azul oscuro, el barrio de San Miguel. A la izquierda, en tono azul celeste, el barrio de Santiago. En el centro los barrios intramuros



la prevalencia de la inversión espiritual frente a la comercial. Así, en la partición de bienes por muerte de Pedro Calle y su mujer Isabel de Brea figuran siete aranzadas y media de viñas en el pago de Largalo, mientras aparece un montante de 1707 reales de vellón como limosna por 610 misas por sus almas, distribuidas entre los conventos de San Francisco, Vera Cruz y Santísima Trinidad, capilla de los Desamparados y parroquia de San Miguel, APNJF, Francisco de Castro, 1697. Fol.11. 
Figura 5. Entrada al compás del convento del Espíritu Santo

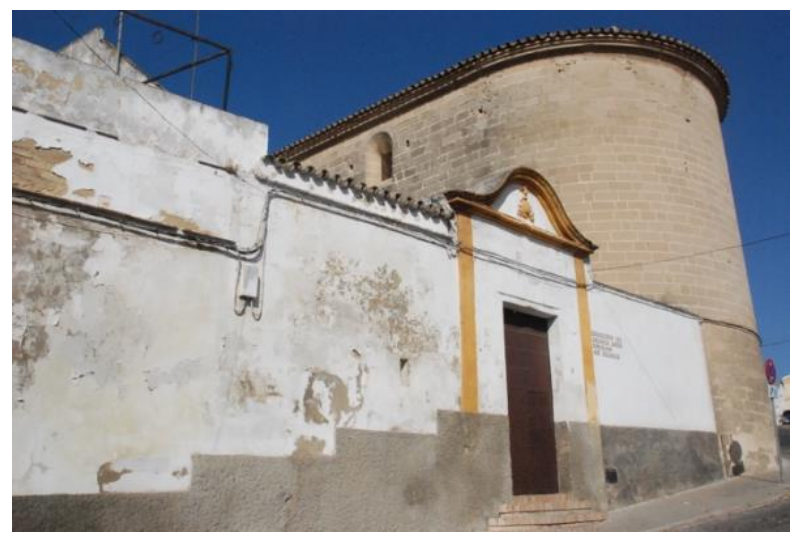

Figura 6. Plano de la Alameda de la ciudad de Jerez. Carlos Manín, 1736

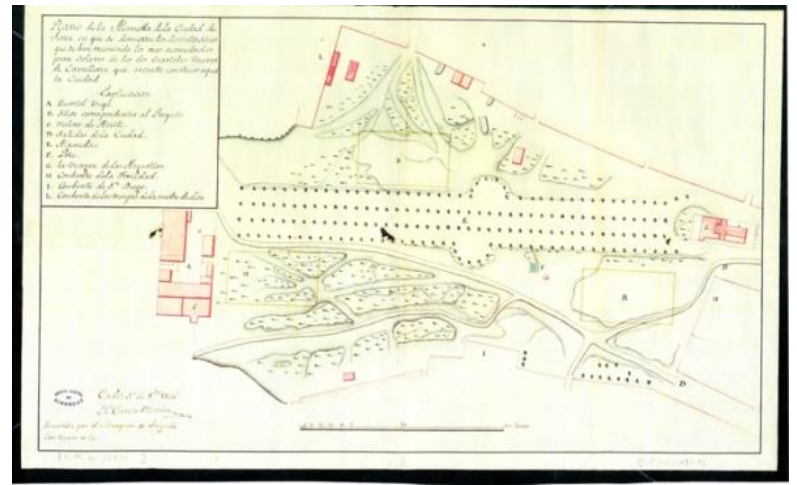

Figura 7. Proyecto de bodegas y graneros para la Cilla en Jerez. (Fotografía José María Guerrero Vega)



Figura 8. Plano de la bodega El Galeón. (Fotografía José María Guerrero Vega)

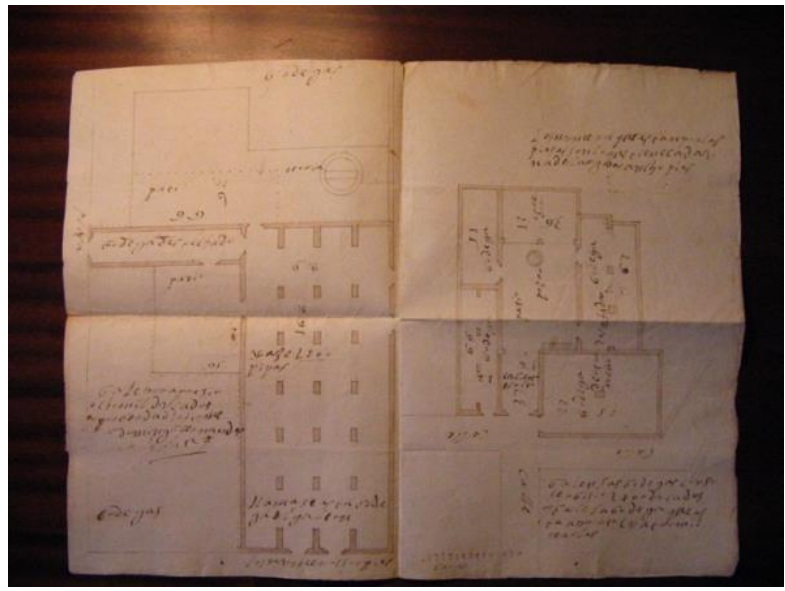

Figura 9. Antiguo granero del convento de Los Descalzos o de la antigua Cilla

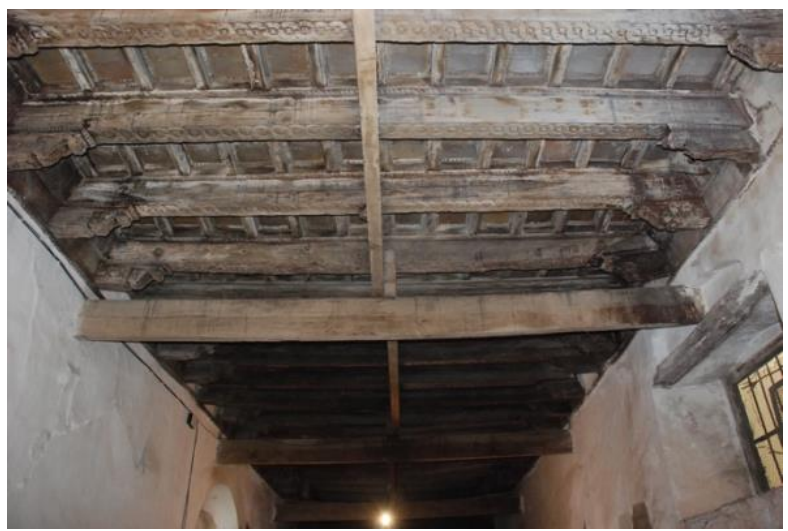

Figura 10. Antiguo granero del convento de Los Descalzos o de la antigua Cilla

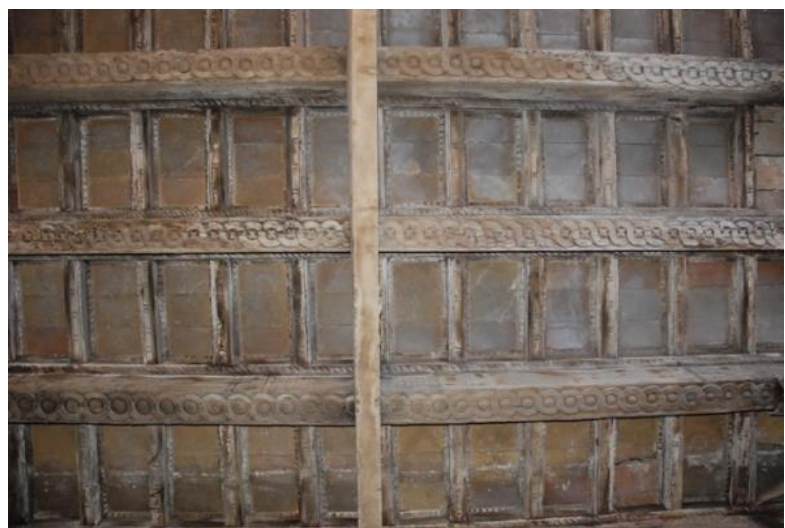


Figura 11. Escalera perteneciente al convento de Los Descalzos o a la antigua Cilla

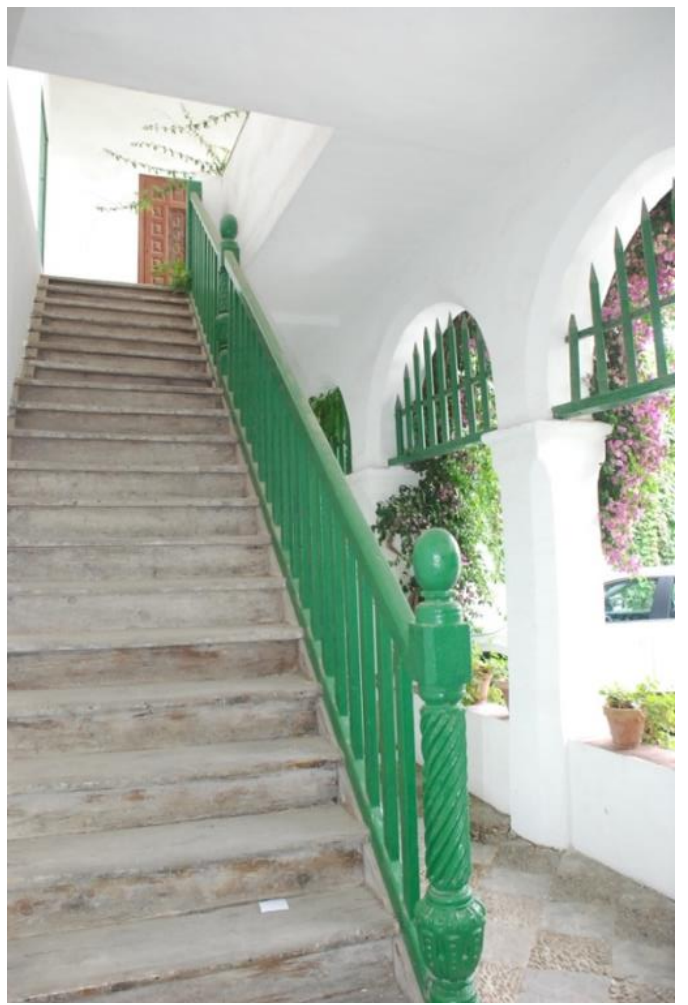

Figura 12. Escalera perteneciente al convento de Los Descalzos o a la antigua Cilla. Detalle del barandal

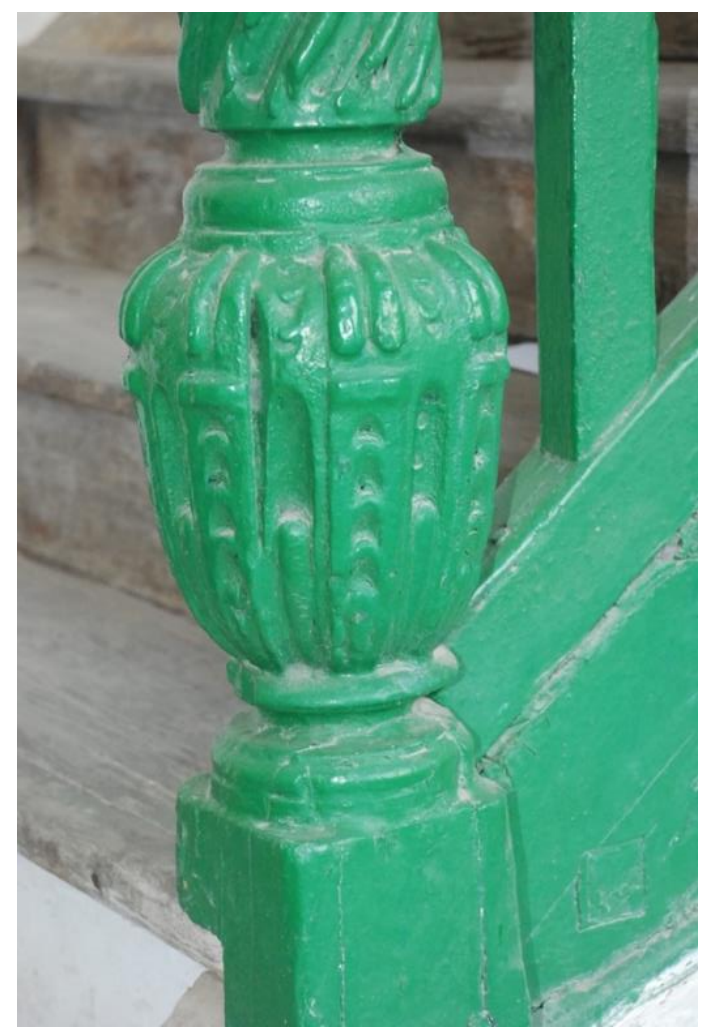

Figura 13. Escalera perteneciente al convento de Los Descalzos o a la antigua Cilla. Detalle del barandal

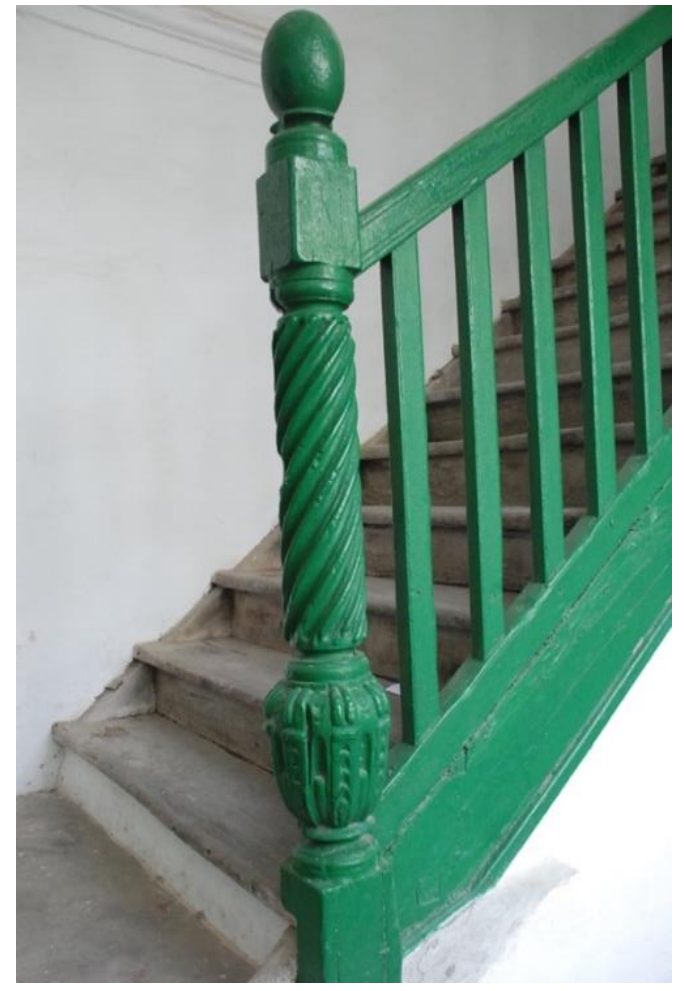

